DOI: 10.1002/cssc.201((will be completed by the editorial staff))

\title{
Dynamics of $\mathrm{Pd}$ on nanocarbon in the direct synthesis of $\mathrm{H}_{2} \mathrm{O}_{2}$
}

\author{
Rosa Arrigo, ${ }^{*}[\mathrm{a}, \mathrm{b}]$ Manfred E. Schuster, ${ }^{[\mathrm{a}]}$ Salvatore Abate, ${ }^{[\mathrm{cc}}$ Sabine Wrabetz, ${ }^{[\mathrm{a}]}$ Kazuhiko Amakawa, ${ }^{[\mathrm{a}]}$ \\ Detre Teschner, ${ }^{[\mathrm{a}]}$ Maria Freni, ${ }^{[\mathrm{b}]}$ Gabriele Centi, ${ }^{\left[{ }^{[\mathrm{C}]}\right.}$ Siglinda Perathoner, ${ }^{[\mathrm{Cl}]}$ Michael Hävecker, ${ }^{\left[{ }^{[d]}\right.}$ Robert \\ Schlögl, ${ }^{[a, b]}$
}

This work aims to clarify the nano-structural transformation accompanying the loss of activity and selectivity for $\mathrm{H}_{2} \mathrm{O}_{2}$ synthesis of $\mathrm{Pd}$ and AuPd nanoparticles supported on $\mathrm{N}$-functionalized carbon nanotubes (NCNTs). High resolution XPS allowed discriminating metallic $\mathrm{Pd}$, electronically-modified metallic $\mathrm{Pd}$ hosting impurities and cationic $\mathrm{Pd}$. This is paralleled by morphological heterogeneity observed by HRTEM where nanoparticles with $2 \mathrm{~nm}$ average size coexist with very small Pd clusters. The morphological distribution of $\mathrm{Pd}$ is modified after reaction through sintering and dissolution/redeposition pathways. The loss of selectivity is correlated to the extent of these processes occurring as a result of the particle instability at the carbon surface. We assign beneficial activity in the selective hydrogenation of oxygen to the Pd clusters with a modified electronic structure as compared to Pd metal or Pd oxides. These beneficial species are formed and stabilized on carbons modified with $\mathrm{N}$ atoms in substitutional positions. The formation of larger metallic Pd particles not only reduces the number of active sites for the synthesis but enhances the activity for the deep hydrogenation to water. The structural instability of the active species is thus detrimental in a dual way. Minimizing the chance of sintering of Pd clusters by all means is thus the key to better performing catalysts.

\section{Introduction}

Recently $\mathrm{H}_{2} \mathrm{O}_{2}$ faces a growing demand in the chemical industry. The conventional multistep synthetic process via anthraquinone presents the disadvantage of high production cost that renders it practicable only for large-scale production. Also, the safety and cost-related issues of the transportation of $\mathrm{H}_{2} \mathrm{O}_{2}$ from the production site to the end-user facility represent disadvantages of the antraquinone process. The on-site realization of a cost effective direct synthesis of $\mathrm{H}_{2} \mathrm{O}_{2}$ from $\mathrm{H}_{2}$ and $\mathrm{O}_{2}$ could expand considerably the application of $\mathrm{H}_{2} \mathrm{O}_{2}$. The Sumitono-Eni process for the synthesis of caprolactame and the Dow-BASF process for the synthesis of propene oxide are examples of oxidation process which aims to use $\mathrm{H}_{2} \mathrm{O}_{2}$ produced on-site via a direct synthesis from $\mathrm{H}_{2}$ and $\mathrm{O}_{2}$. ${ }^{[1,2]}$

From the large variety of literature and patents on the topic, ${ }^{[3,4]}$ it is evinced that effective catalytic systems for the direct synthesis of $\mathrm{H}_{2} \mathrm{O}_{2}$ from $\mathrm{H}_{2} / \mathrm{O}_{2}$ involve the use of supported $\mathrm{Pd}$ catalysts in a slurry of $\mathrm{H}_{2} \mathrm{O} / \mathrm{CH}_{3} \mathrm{OH}$ and in the presence of $\mathrm{H}_{2} \mathrm{SO}_{4}$ and halides to achieve good activity and selectivity to $\mathrm{H}_{2} \mathrm{O}_{2}{ }^{[5-7]}$

The major problems of the direct synthesis toward commercialization are related to the safety of the process as well as the selectivity. The apparent simplicity of the synthesis reaction is accompanied, in reality, by a complex network of thermodynamically favored deep hydrogenation reactions to $\mathrm{H}_{2} \mathrm{O}$, as shown in Scheme 1. Important contributions to the development of selective catalysts for the $\mathrm{H}_{2} \mathrm{O}_{2}$ direct synthesis were made by Hutchings and co-workers, ${ }^{[8-10]}$ through the application of encapsulated $\mathrm{Pd}$-nanoparticles obtained via sol- immobilization on $\mathrm{C}$ support, the introduction of C-supported $\mathrm{Pd}-\mathrm{Au}$ nanoparticles and through the use of an acidic $\mathrm{C}$ support. However, for the industrialization of the process, the selectivity and the life time of these catalysts needs further improvement. $^{[5]}$ The shell-protected Pd-nanoparticles suffer instability, resulting in a rapid loss of the initial extraordinary high selectivity and activity through a quick transformation into an unprotected and thus unselective form. ${ }^{[8,11]}$ The transient catalytic performance of the PVA-protected Pd nanoparticles is related to the peculiar dissolution of $\mathrm{O}, \mathrm{H}$, and $\mathrm{C}$ in the near surface region ${ }^{[12-17]}$ that depends on the reactant gas phase chemical potential, ${ }^{[11-13]}$ the fluid-dynamic conditions $[11,18,19]$ and the morphological transformations of the nanoparticles following de-protection. ${ }^{[19-21]}$ Scheme 1 illustrates how the desired selectivity of the hydrogenation reaction of oxygen depends on two chains of consecutive reactions. One chain is given by the ratio between dissociative oxygen activation and the abundance of hydrogen: more hydrogen helps forming faster the product but also leads to the thermodynamically more stable deep hydrogenation product. The other reaction chain is given by the ratio of desorption and re-adsorption of the desired product. It is obvious that a delicate optimization of the electronic structure of $\mathrm{Pd}$ will be critical. Reaction parameters but also solvents and kinetic site blockers as additives to the reaction system can be used for fine-tuning. The support can contribute through covalent interaction with Pd leading to wetting of particles as well as to strained systems. 


\section{ChemSusChem}

\section{Full Papers \\ www:chemsuschem.org}

Recently we have shown ${ }^{[20]}$ that by tuning the metal/C support interaction it is possible controlling the morphology and the stability of the nanoparticles thereby influencing the chemisorption of the reactants as well as the morphological transformation of the nanoparticles under reaction conditions. Functionalization of CNT by $\mathrm{NH}_{3}$ at high temperature (873K) affords a $\mathrm{Pd} /$ support interaction with a beneficial effect on the activity in the direct $\mathrm{H}_{2} \mathrm{O}_{2}$ synthesis ${ }^{[11]}$ and in alcohol oxidation. [20-21] PVA-protected Pd nanoparticels on NCNT show comparatively high performance with respect to $\mathrm{Pd}$ nanoparticles on different supports $\left(\mathrm{Al}_{2} \mathrm{O}_{3}, \mathrm{SiO}_{2}, \mathrm{SBA}-15, \mathrm{CNT}\right)$ $[11,19]$, but also only until they become de-protected.

In this work we elucidate the role of the $\mathrm{Pd} / \mathrm{C}$ support interaction and the effects of the interaction of reactants with the bare support by using two supports stemming from the same CNT that were modified with $\mathrm{NH}_{3}$ at $473 \mathrm{~K}$ and $873 \mathrm{~K}$. These NCNT supports strongly differ in chemical behavior. ${ }^{[22]}$ The NCNT873K are characterized by an overall hydrophobic surface with few strong N basic sites, while NCNT473K are characterized by overall hydrophilic surface with a distribution of $\mathrm{N}$ and $\mathrm{O}$ basic and acid sites. The implications of these chemical properties on the nanoparticle morphology and their reactivity will be discussed. Finally the direct modification of the $\mathrm{Pd}$ electronic structure by alloying is an orthogonal vector of modifying the reactivity. ${ }^{[10,23-28]}$ In practical catalysts all these lines of control of reactivity will contribute to the performance making the functional discrimination and quantification of $\mathrm{Pd}$ species a challenging task that is attempted in this work.

To achieve this goal, a comparative structural analysis of differently performing Pd-based samples by means of transmission electron microscopy (TEM), X-ray photoemission spectroscopy (XPS) and microcalorimetry are applied. The samples are referred as $\mathrm{Pd}$ and $\mathrm{PdAu}$ on two types of $\mathrm{N}$ functionalized carbon nanotubes, NCNT473K and NCNT873K, where $473 \mathrm{~K}$ and $873 \mathrm{~K}$ refer to the temperature of the functionalization in $\mathrm{NH}_{3}$. Thus, 4 samples are investigated in this work: Pd_873, Pd_473, PdAu_873 and PdAu_473. To follow the structural changes of $\mathrm{Pd}$ upon reaction, samples used for $12 \mathrm{~min}$ and for $3 \mathrm{~h}$ of reaction were characterized deeply. These reaction times correspond to the states of highest selectivity and deactivation respectively. Indication as PdAu_473u refers to samples after $12 \mathrm{~min}$ of reaction, if not differently indicated. Samples after $3 \mathrm{~h}_{2} \mathrm{O}_{2}$ decomposition are indicated as PdAu_473*.

[a] Dr. R. Arrigo, Dr. M. E. Schuster, Dr. S. Wrabetz, K. Amakawa, Dr. D. Techner, Prof. R. schlögl

Dept. Anorganische Chemie Fritz-Haber-Institut der Max-Planck Gesellschaft, Faradayweg 4-6, 14195 Berlin, Germany E-mail: arrigo@fhi-berlin.mpg.de

[b] Max-Planck Institut für Chemische Energiekonversion, Stiftstr. 34 - 36, 45470 Mülheim an der Ruhr, Germany

[c] Dr. S. Abate, Prof. G. Centi, Prof. S. Perathoner, Dr. M. Freni Dipartimento di Chimica industriale, Università degli Studi di Messina, V.le F. Stagno D'Alcontres 31, 98166 Messina

[d] Dr. M. Hävecker, Helmholtz-Zentrum Berlin, Albert-Einstein-Str. 15, 12489 Berlin, Germany

Supporting information for this article is available on the WWW under http://dx.doi.org/10.1002/cssc.20xxxxxxx.((Please delete if not appropriate))

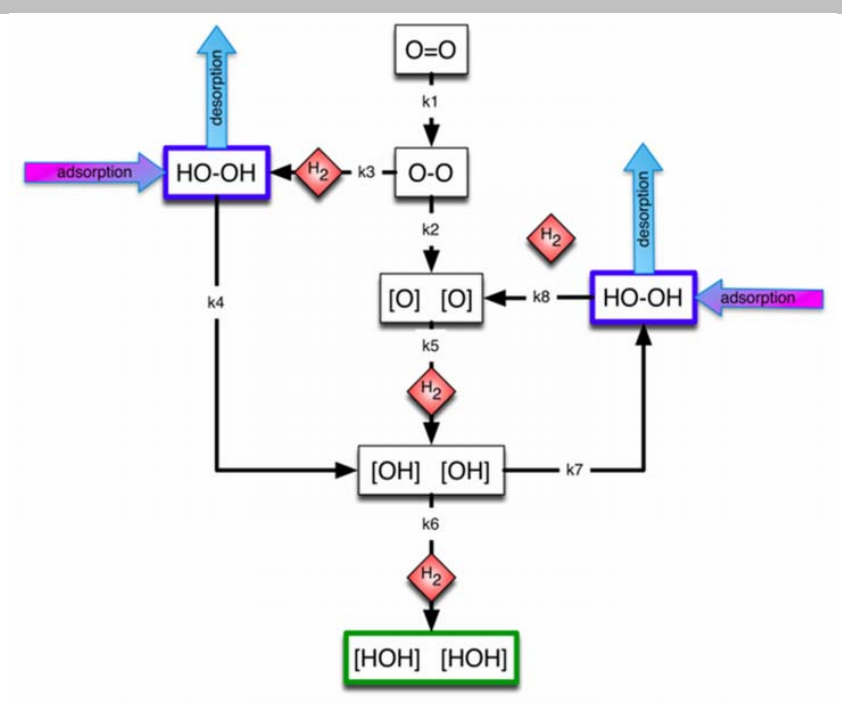

Scheme 1. Reaction network of the direct $\mathrm{H}_{2} \mathrm{O}_{2}$ synthesis: direct formation of $\mathrm{H}_{2} \mathrm{O}_{2}(\mathrm{a})$ and $\mathrm{H}_{2} \mathrm{O}$ (b), and decomposition of $\mathrm{H}_{2} \mathrm{O}_{2}$ to $\mathrm{H}_{2} \mathrm{O}$ (c).

\section{Results and Discussion}

\section{Catalytic data}

In this work we focus on a comparative analysis of the catalytic performance of different $\mathrm{Pd}$-based catalyst in the direct synthesis of $\mathrm{H}_{2} \mathrm{O}_{2}$ from $\mathrm{H}_{2} / \mathrm{O}_{2}$ in the ratio $1 / 7$ and in the presence of $\mathrm{H}_{2} \mathrm{SO}_{4}$. This ratio was chosen as it gives the highest long-term selectivity. ${ }^{\left[{ }^{29]}\right.}$ At higher $\mathrm{H}_{2} / \mathrm{O}_{2}$ ratio, the initial reaction rate is higher but the selectivity decreases earlier as well as fast catalyst deactivation occurs. ${ }^{[29]}$ Also the addition of $\mathrm{H}_{2} \mathrm{SO}_{4}$ was beneficial for the $\mathrm{H}_{2} \mathrm{O}_{2}$ productivity with an increase of more than the $50 \%$. The behavior of these catalysts in the $\mathrm{H}_{2} \mathrm{O}_{2}$ decomposition in the presence of $\mathrm{H}_{2}$ and $\mathrm{H}_{2} \mathrm{SO}_{4}$ is also discussed.

Decomposition tests in $\mathrm{N}_{2}$ did not lead to any $\mathrm{H}_{2} \mathrm{O}_{2}$ conversion suggesting that on this type of catalysts the main decomposition pathway is the successive hydrogenation (Scheme 1). Table 1 summarizes the $\mathrm{H}_{2} \mathrm{O}_{2}$ productivity and the selectivity for the catalysts investigated. For Pd_873 the selectivity is high (93\%) for the first 20 min of reaction time; an inversion in selectivity towards the formation of $\mathrm{H}_{2} \mathrm{O}$ occurs at around $50 \mathrm{~min}$ of reaction and decreases to $30 \%$ at $90 \mathrm{~min}$ of reaction. $\mathrm{Pd} 473$ is the most unselective catalyst showing a high selectivity of $93 \%$ within the first $10 \mathrm{~min}$, which decreases rapidly reaching at the end of the reaction $7 \%$, the lowest value among the catalysts. For PdAu_873 the selectivity is stable for $40 \mathrm{~min}$ at $93 \%$ and decreases thereafter with a similar trend observed for the monometallic catalysts. PdAu_473 is exceptionally poor as it shows low catalytic activity; as consequence the selectivity decreases slowly and after 120 min of reaction the selectivity is only $20 \%$. At the same selectivity the Pd based samples immobilized on NCNT873K reveal superior catalytic performance and among them the monometallic sample shows extraordinary catalytic activity also if compared to literature (table 2). ${ }^{[8-10,30-32]}$ 


\begin{tabular}{|c|c|c|c|c|c|c|c|c|}
\hline \multirow{2}{*}{$\begin{array}{l}\text { Time } \\
(\mathrm{min})\end{array}$} & \multicolumn{2}{|c|}{ Pd_873 } & \multicolumn{2}{|c|}{ Pd_473 } & \multicolumn{2}{|c|}{ PdAu_873 } & \multicolumn{2}{|c|}{ PdAu_473 } \\
\hline & A & B & A & B & A & B & A & B \\
\hline 10 & 57 & 94 & 38 & 91 & 25 & 95 & 0 & 94 \\
\hline 20 & 248 & 93 & 239 & 39 & 50 & 97 & 15 & 93 \\
\hline 40 & 503 & 78 & 435 & 24 & 67 & 96 & 23 & 89 \\
\hline 60 & 590 & 44 & 339 & 22 & 219 & 62 & 23 & 86 \\
\hline 90 & 510 & 25 & 241 & 15 & 319 & 39 & 24 & 66 \\
\hline 120 & 657 & 31 & 227 & 7 & 449 & 33 & 25 & 20 \\
\hline 180 & 721 & 29 & 162 & 12 & 380 & 38 & 30 & 22 \\
\hline
\end{tabular}

[A] $\mathrm{H}_{2} \mathrm{O}_{2}$ produced [mol kg-1 $\mathrm{h}^{-1}$ ]; [B] selectivity [\%]

Figure 1 reports the cumulative production of $\mathrm{H}_{2} \mathrm{O}_{2}(\mathrm{~A})$ and of $\mathrm{H}_{2} \mathrm{O}(\mathrm{B})$ vs time on stream in the synthesis test and the $\mathrm{H}_{2} \mathrm{O}_{2}$ decomposed vs time on stream $(\mathrm{C})$ in the decomposition tests. The synthesis and the decomposition reactions are characterized by an induction time of around $10 \mathrm{~min}$; after this induction time, the rate of $\mathrm{H}_{2} \mathrm{O}_{2}$ formation during the synthesis (indicated by the tangent to the curve) in the first 20 minutes increase rapidly for the monometallic samples. Above $20 \mathrm{~min}$, among the monometallic samples the Pd_873 shows better performance than the $\mathrm{Pd}$ _473: in fact for the latter sample the rate of $\mathrm{H}_{2} \mathrm{O}_{2}$ formation after 50 min of reaction is very low, indicating the deactivation of the catalysts toward the direct $\mathrm{H}_{2} \mathrm{O}_{2}$ synthesis.

\begin{tabular}{|ccccc|}
\hline Table 2. Performance of $\mathrm{Pd} / \mathrm{C}$ catalysts from literature & \\
\hline Catalyst & $\begin{array}{c}\text { Production } \\
\left(\mathrm{mol} \mathrm{kg}^{-1} \mathrm{~h}^{-1}\right)\end{array}$ & $\begin{array}{c}\text { Selectivity } \\
(\%)\end{array}$ & $\begin{array}{c}\text { reaction } \\
\text { time } \\
(\mathrm{min})\end{array}$ & $\begin{array}{c}\text { Reaction } \\
\text { conditions/ } \\
\mathrm{O}_{2}: \mathrm{H}_{2}\end{array}$ \\
\hline $\mathrm{Pd}\{\mathrm{Au}\} / \mathrm{C}^{[8]}$ & 1384 & $\mathrm{NA}$ & 0.5 & Batch/2 \\
$\mathrm{PdAu} / \mathrm{C}^{[10]}$ & 143 & $\mathrm{NA}$ & 30 & \\
$\mathrm{Pd} / \mathrm{C}^{[31]}$ & 175 & $>98$ & 30 & Batch/2 \\
$\mathrm{Pd} / \mathrm{C}^{[32]}$ & 110 & 80 & 30 & Batch/2 \\
$\mathrm{PdAu} / \mathrm{C}^{[32]}$ & 102 & $\mathrm{NA}$ & 30 & Batch/2 \\
\hline
\end{tabular}

The PdAu_873 in the direct $\mathrm{H}_{2} \mathrm{O}_{2}$ synthesis is characterized by a slower initial reactivity below 40 min which increases rapidly at longer times.

All catalysts apart from the PdAu_473 sample exhibit a similar performance in the $\mathrm{H}_{2} \mathrm{O}_{2}$ hydrogenation (Figure $1 \mathrm{C}$ ). However, the $\mathrm{H}_{2} \mathrm{O}$ yields in the direct synthesis are much higher than in the decomposition test suggesting that in the direct synthesis, the reaction to water via enhanced dissociation of oxygen is the predominant pathway as compared to the consecutive deep hydrogenation of readsorbed $\mathrm{H}_{2} \mathrm{O}_{2}$ (Scheme 1).
For the Pd_473 sample both yields in the hydrogenation of $\mathrm{H}_{2} \mathrm{O}_{2}$ and in the direct synthesis exhibit similar trends. The decomposition of $\mathrm{H}_{2} \mathrm{O}_{2}$ under $\mathrm{H}_{2}$ may thus occur on the same sites that convert selectively $\mathrm{O}_{2}$ into $\mathrm{H}_{2} \mathrm{O}_{2}$ during the synthesis. Alternatively two hypothetically different sites for both reactions should be present in similar amounts and similar intrinsic conversion efficiencies.

a

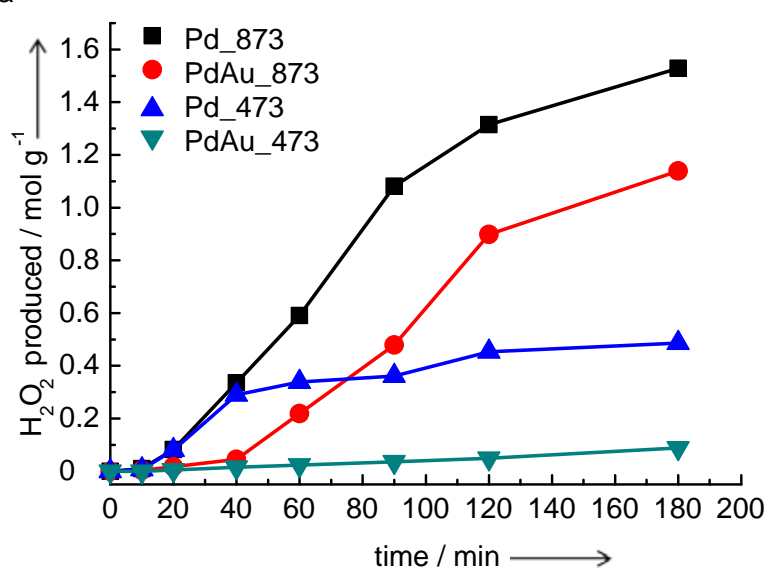

b

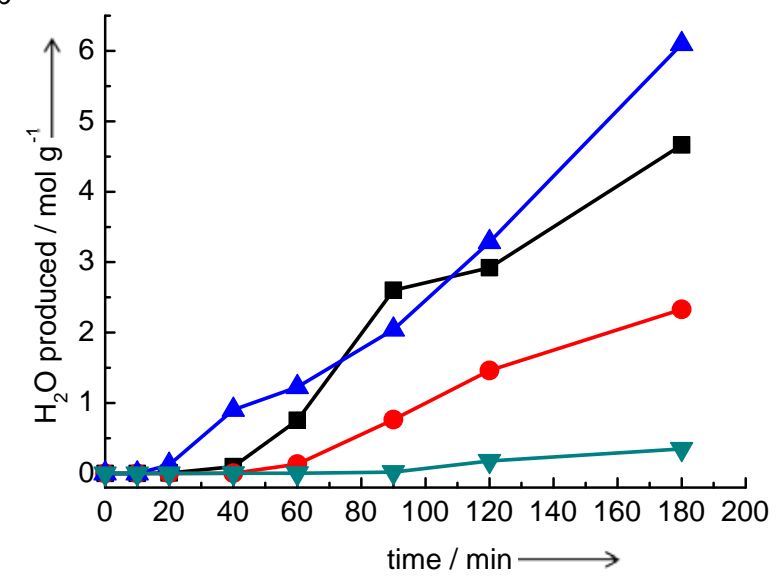

C

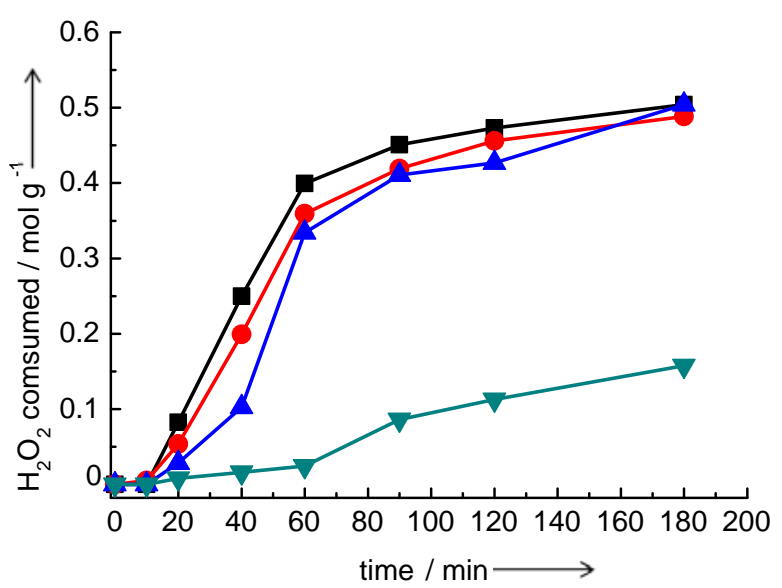

Figure 1. (A) mol of $\mathrm{H}_{2} \mathrm{O}_{2}$ formed during the $\mathrm{H}_{2} \mathrm{O}_{2}$ synthesis from a mixture of $\mathrm{H}_{2} / \mathrm{O}_{2}$ 1/7. B) mol of $\mathrm{H}_{2} \mathrm{O}$ formed during the $\mathrm{H}_{2} \mathrm{O}_{2}$ synthesis from a mixture of $\mathrm{H}_{2} / \mathrm{O}_{2}$ 1/7. C) mol of $\mathrm{H}_{2} \mathrm{O}_{2}$ decomposed during $\mathrm{H}_{2} \mathrm{O}_{2}$ decomposition test in the presence of $\mathrm{H}_{2}$ (for: $\mathrm{Pd} 873$ (black curve); $\mathrm{Pd} 4773$ (blue curve); PdAu_873 (red curve); PdAu_473 (green curve). 


\section{ChemSusChem}

\section{Full Papers \\ wwvw.chemsuschem.org}

During the synthesis, already after 20 min of reaction, some chemical modification of the $\mathrm{Pd}$ favours the unselective direct conversion of $\mathrm{O}_{2}$ to $\mathrm{H}_{2} \mathrm{O}$ while these modifications are inactive for the $\mathrm{H}_{2} \mathrm{O}_{2}$ hydrogenation/decomposition.

The maximum yield to $\mathrm{H}_{2} \mathrm{O}$ in the decomposition test for the Pd_873, sample is only slightly higher than for the other samples and the rate decreases after $50 \mathrm{~min}$ of reaction. In the direct synthesis the rate of $\mathrm{H}_{2} \mathrm{O}_{2}$ formation still increases after $50 \mathrm{~min}$ of reaction and only decreases after $100 \mathrm{~min}$. Therefore after 50 min of reaction under $\mathrm{H}_{2}$, the $1 \mathrm{e}$ - transfer sites for the hydrogenation of $\mathrm{H}_{2} \mathrm{O}_{2}$ are lost, while under $\mathrm{O}_{2} / \mathrm{H}_{2}$ the surface is still able to selectively activate $\mathrm{O}_{2}$ to $\mathrm{H}_{2} \mathrm{O}_{2}$. This indicates the dynamics of the $\mathrm{Pd}$ species being activated to different reactivity in hydrogen and mixtures of $\mathrm{H}_{2}$ and $\mathrm{O}_{2}$. The underlying mechanism is associated with a modification of the $\mathrm{Pd}$ in the presence of oxygen forming likely sub-surface compounds, as will be shown later on, resulting in a modification of the electronic surface structure. Without this sub-surface oxygen a $\mathrm{Pd}$ hydride is assumed to be the operating state of the metal. The fact that such transformations occur readily at ambient temperature indicates the relevance of the small size of the beneficial active particles. In summary, we distinguish for all samples three regions of reactivity correlated to different structural changes: the region from 0 to $10 \mathrm{~min}$ of reaction time in which the selectivity is high for all catalysts with low activity for both synthesis and decomposition.

After this induction time, the region between 10 and $40 \mathrm{~min}$ is dominated by the formation of $\mathrm{H}_{2} \mathrm{O}_{2}$, with selectivity above $90 \%$ for all catalyst except for $\mathrm{Pd}$ _473. At longer reaction times we observed a fast decrease of the selectivity. More precisely, the change of selective behaviour occurs at different time: around $10 \mathrm{~min}$ for the Pd_473; around $50 \mathrm{~min}$ for the Pd_873 and after $75 \mathrm{~min}$ for the PdAu_873.

The exposed metal surface area was determined by $\mathrm{CO}$ chemisorption for the used samples after 12 min of reaction as an attempt to normalize the catalytic data. Figure 2 reports the $\mathrm{H}_{2} \mathrm{O}_{2}$ produced and the selectivity to $\mathrm{H}_{2} \mathrm{O}_{2}$ at 20 minutes versus the reactive surface area for all samples investigated. No direct correlation was found between the exposed surface area and the productivity to $\mathrm{H}_{2} \mathrm{O}_{2}$ : for instance the $\mathrm{Pd} \_873$ shows similar productivity than the $\mathrm{Pd} 473$ although the last one exhibits a higher surface area. This indicates that the number of active sites is not proportional to the number of Pd sites. We have to expect inhomogeneity in the geometric and electronic structures as origin of this behaviour.

\section{Morphology of Pd/NCNT}

The microstructure of the samples fresh and after catalytic reaction is reported in this section. In agreement with earlier literature, ${ }^{[20,33]}$ the $\mathrm{Pd}$ and $\mathrm{Au}$ nanoparticles exhibit fcc structure and expose mainly $\{111\}$ and $\{200\}$ planes. The nanoparticles are interacting with the NCNT surface and are partially decorated at their surface by the C-overlayer from the PVA as shown in Fig.3A for the PdAu_473. The HAADF-STEM image Fig.3B reveals besides the nanoparticles visible in the HRTEM, additional metal atoms decorating the surface of the NCNT as well as the Au nanoparticles as indicated by the arrows. The EDX mapping (Fig.3C for the PdAu_473 and Fig.S1 for the PdAu_873) reveals that the nanoparticles are composed by both $\mathrm{Pd}$ and $\mathrm{Au}$ while the atomically dispersed metal species on the $C$ support are only $\mathrm{Pd}$. The capability of the carbon surface to immobilize Pd depends strongly on its surface chemistry, i.e. the distribution of defects including functional groups. This implies morphological and size

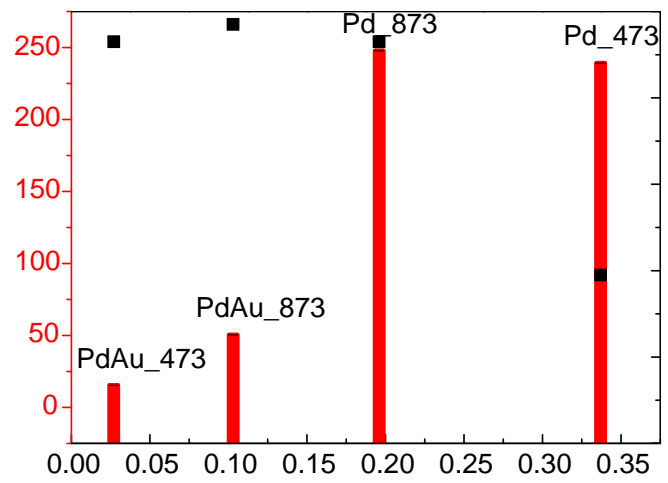

Figure 2. $\mathrm{H}_{2} \mathrm{O}_{2}$ cumulative production $\left(\mathrm{molKg}^{-1} \mathrm{~h}^{-1}\right)$ and selectivity at $20 \mathrm{~min}$ vs specific $\mathrm{Pd}$ surface area $\left(\mathrm{m}^{2} \mathrm{~g}^{-1}\right)$ as determined by $\mathrm{CO}$ chemisorption.

heterogeneities of the metal nanoparticles as consequence of the distribution of surface species at the carbon support. $[20,22]$ The functional groups on the carbon surface act as ligands for clustered or atomically dispersed Pd (Fig.3B-C). This immobilization pathway is favoured on hydrophilic surface through ion-exchange such as $\mathrm{C}-\mathrm{O}-\mathrm{H}$ for $\mathrm{C}-\mathrm{O}-\mathrm{Pd}$. In the case of the sol-immobilization route of preformed nanoparticles, the interaction between the initial PVA-protected nanoparticles and the carbon surface should be realized. Its absence leads to agglomeration and it is pronounced among the monometallic samples on the NCNT473 support (Fig. S2). Figure 4A exemplifies a typical morphology that distinguish $\mathrm{Pd}$ from $\mathrm{Au}$ : $\mathrm{Au}$ forms always well-shaped round nanoparticles with little contact to the support independently of the particles size (nanoparticles with higher contrast) In contrast small $\mathrm{Pd}$ nanoparticles assume a raft-like morphology on the NCNT (Pd nanoparticles are identified by the lower contrast) where strong metal-support interaction occurs. ${ }^{[33]}$ In agreement with a previous report on $\mathrm{Au}$ and $\mathrm{Pd}$ nanoparticles synthesized via sol-immobilization, ${ }^{[34]}$ the distribution of the particle sizes in the fresh monometallic $\mathrm{Pd}$ catalysts is much narrower than for the fresh bimetallic catalysts and the average particles size is also smaller (Table 3). 


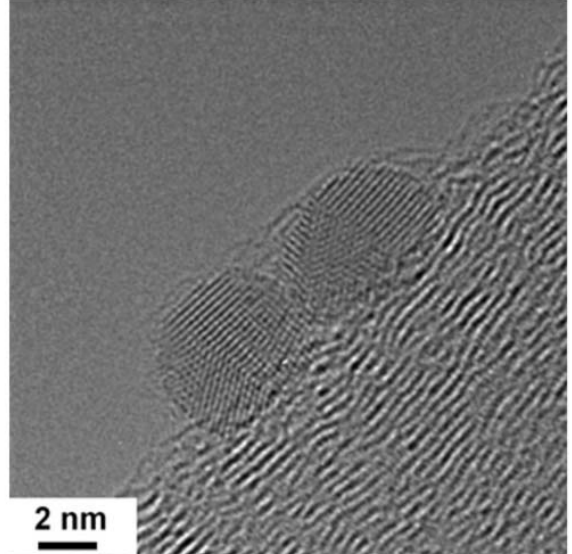

b

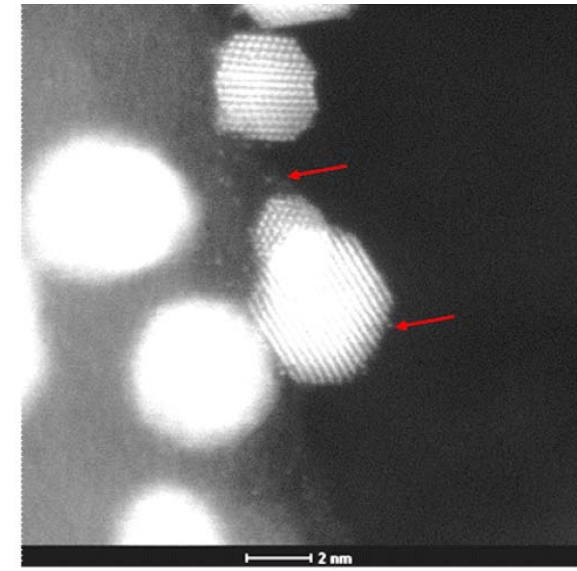

C
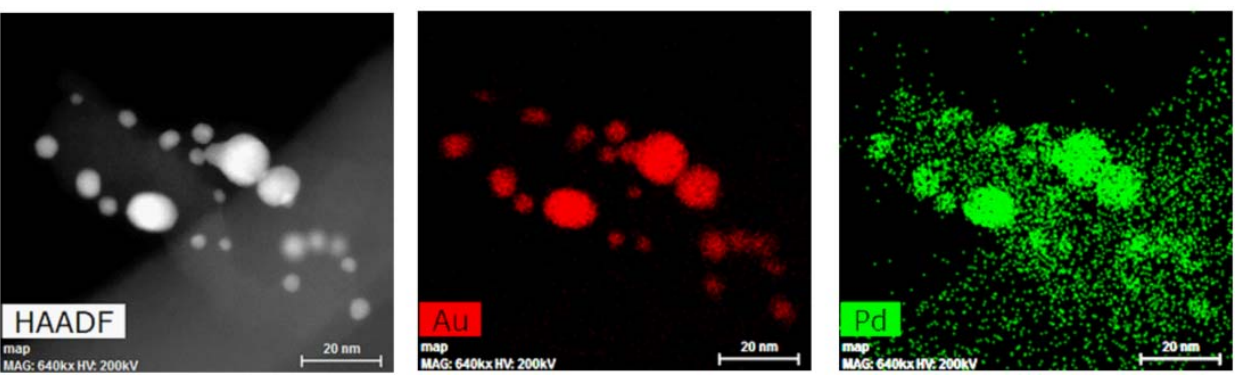

Figure 3 HRTEM on PdAu_473 (A) and HAADF-STEM (B). EDX mapping (C).

a

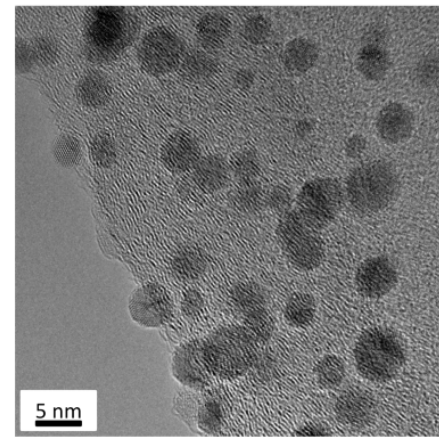

d

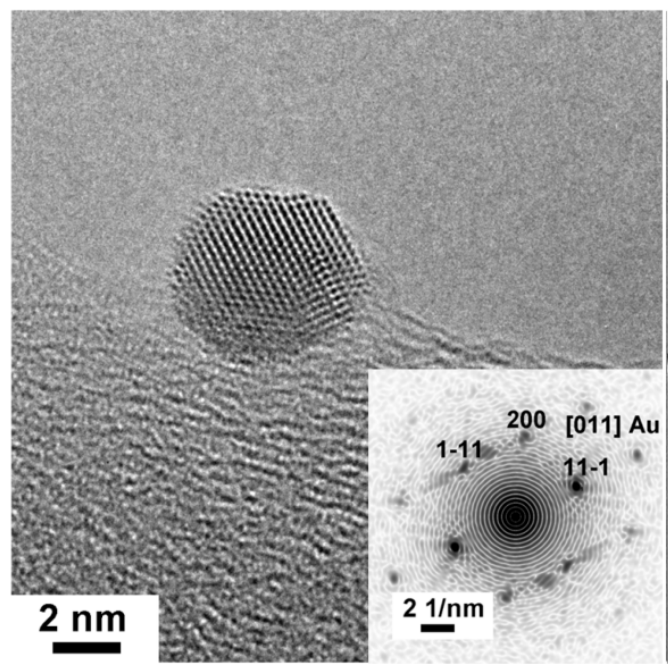

e

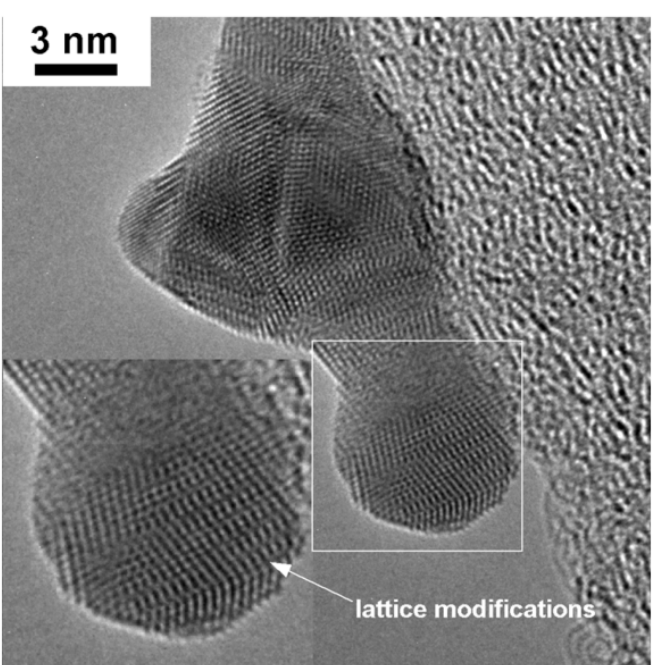

Figure 4. TEM on PdAu 873 (A); PdAu 873u (B) PdAu 873u after 3h reaction; HRTEM on nanoparticles on PdAu 873 (D); HRTEM on sintered nanoparticles on PdAu_873u after $3 \mathrm{~h}$ reaction $(\mathrm{E})$. 


\section{ChemSusChem}

\section{Full Papers \\ wwww.chemsuschem.org}

\begin{tabular}{|c|c|c|c|c|}
\hline & Pd_873 & Pd_473 & PdAu_873 & PdAu_473 \\
\hline fresh & $\begin{array}{l}1.7 \\
\pm 0.5\end{array}$ & $\begin{array}{l}2.3 \\
\pm 0.5\end{array}$ & $\begin{array}{l}7.8 \\
\pm 4.8\end{array}$ & $\begin{array}{l}4.0 \\
\pm 1.6\end{array}$ \\
\hline $\begin{array}{l}\text { used } 12 \\
\text { min }\end{array}$ & $\begin{array}{l}1.8 \\
\pm 1.4\end{array}$ & $\begin{array}{l}2.9 \\
\pm 0.9\end{array}$ & $\begin{array}{l}3.8 \\
\pm 0.9\end{array}$ & $\begin{array}{l}3.8 \\
\pm 1.5\end{array}$ \\
\hline
\end{tabular}

The impact of the reaction conditions on the particles morphology accounts for two morphological modifications. Initially, the detachment of the protective C-overlayer from the nanoparticles in the liquid phase reaction allows the particles to agglomerate when no strong metal-support interaction is established.

We can observe the transformation of such particles in the TEM image in Figure 4 for the fresh PdAu_873 (A), the used $\mathrm{PdAu} 873 \mathrm{u}$ at $12 \mathrm{~min}$ reaction $(\mathrm{B})$ and after $3 \mathrm{~h}$ reaction $(\mathrm{C})$. Already after 12 min of $\mathrm{H}_{2} \mathrm{O}_{2}$ synthesis, the catalyst PdAu_873 suffers agglomeration of the nanoparticles. A more severe morphological change occurs after $3 \mathrm{~h}$ of reaction due to sintering. The HRTEM for PdAu_873 and PdAu_873u after 3h of reaction are reported in (D) and (E) and emphasize the multiple twinning following sintering through particle coalescence.

The extent of the morphological changes induced by the reactive atmosphere is more pronounced for the monometallic samples. ${ }^{[3]}$ The particles size distribution in Figure S3 shows for the monometallic Pd_873 after 12 min reaction substantial agglomeration although small particles are still abundantly present (Figure S3 A, B). The frequency distribution of the radius evolves into a bimodal form with a high abundance of small nanoparticles and few very big nanoparticles in a broad size range. In the case of the $\mathrm{Pd}$ _473, the particle radius distribution became broader but maintains a Gaussian form. The average particle size for all catalysts is summarized in Table 3. The capability of the NCNT to stabilize the Pd nanoparticles giving rise to the occurrence of small particles is correlated to the nature of the $\mathrm{N}$ functional groups. The $\mathrm{Pd} \_873$ sample suffers more agglomeration than the $\mathrm{Pd} \_473$. However, this is not due to the strength of the metal-support interaction in the first place, but we attribute this to the higher ion exchange capacity on the NCNT473 which allows the redeposition of dissolved cationic Pd (see XPS section). A respective contrast is also observed in the HAADF STEM for $\mathrm{PdAu} 473 \mathrm{u}$ after $3 \mathrm{~h}$ of $\mathrm{H}_{2} \mathrm{O}_{2}$ synthesis (Figure 5). The cloudy contrast, which was less pronounced in the fresh samples (Figure $3 \mathrm{C}$ ), arises from molecular $\mathrm{Pd}$ species with ligands of light atoms $(\mathrm{C}, \mathrm{O}, \mathrm{H})$ resulting from dissolution/re-deposition of $\mathrm{Pd}$ in the liquid phase reaction. ${ }^{[35]}$

Similar morphological transformations are observed for the $\mathrm{PdAu} 473^{*}$ sample (after $3 \mathrm{~h}$ of $\mathrm{H}_{2} \mathrm{O}_{2}$ decomposition test) as characterized by TEM, HAADF-STEM and EDX mapping (Fig. S4). TEM indicates severe sintering after $3 \mathrm{~h}$ of decomposition reaction and the STEM image shows besides big particles some agglomerates of small nanoparticles representing likely Pd compounds with here invisible light atom ligands. The EDX mapping on this region however reveals intensity from both $\mathrm{Pd}$ and $\mathrm{Au}$.

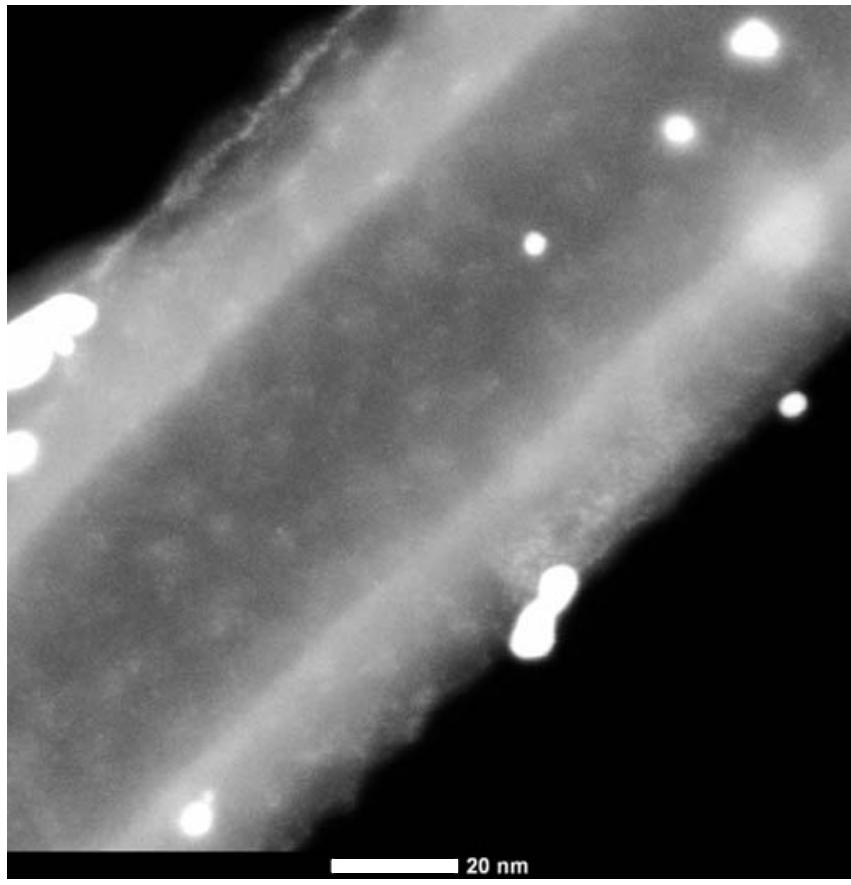

Figure 5. HAADF-STEM on PdAu_473u after $3 \mathrm{~h}$ of reaction.

In summary the reactive atmosphere induces several processes affecting the particles size distribution: agglomeration of particles carrying ligands and sintering of bare nanoparticles less stabilized at the NCNT surface. Dissolved $\mathrm{Pd}$ are re-deposited as small $\mathrm{Pd}$ clusters at the hydrophilic sites of the NCNT surface. In addition some strongly bound very small Pd nanoparticles with strong metalsupport interaction remain intact as small entities even after extended reaction testing. 
a

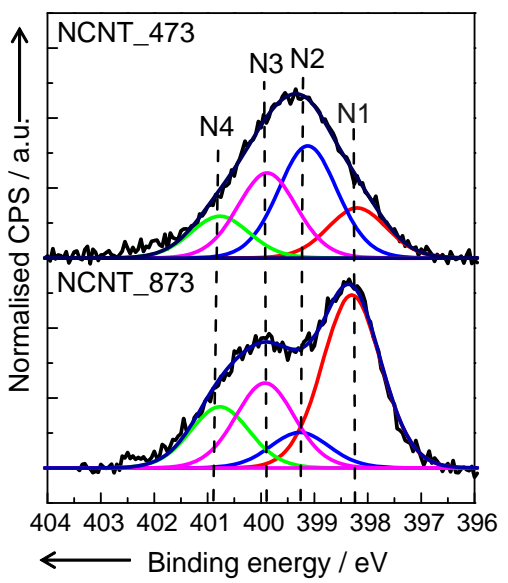

b

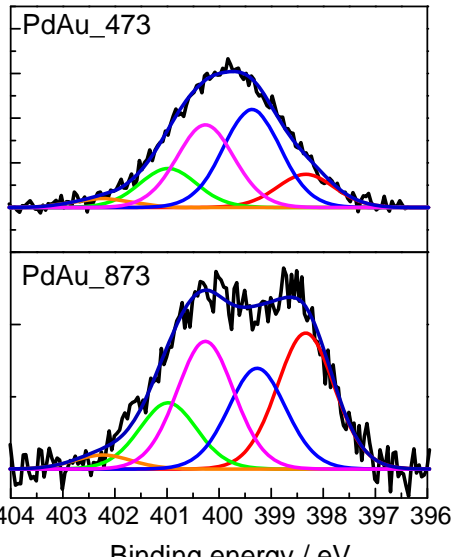

Binding energy / eV
C

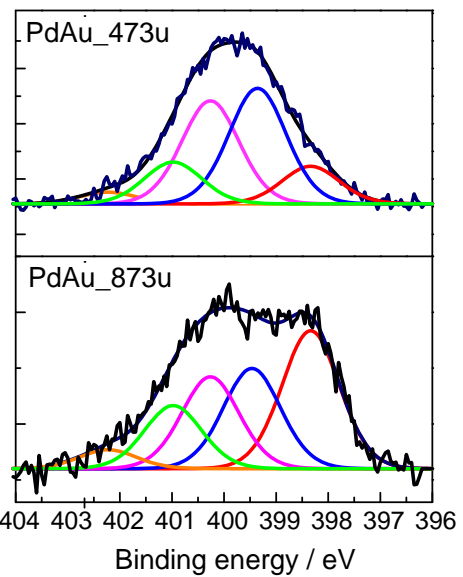

Figure 6. N1s XP spectra for: NCNT (A), PdAu samples fresh (B) and used after 12 min of reaction (C); NCNT functionalized at $473 \mathrm{~K}$ (top) and 873 (bottom).

\section{Nature of the nitrogen species on NCNT by XPS}

The N1s spectra for the two N-CNTs were previously published in ${ }^{[22]}$ and are here reproduced in Figure 6A together with the spectra after $\mathrm{Au}$ and $\mathrm{Pd}$ loading in Figure $6 \mathrm{~B}$ and for used catalysts in Figure $6 \mathrm{C}$. A broad distribution of nitrogen species is introduced by the $\mathrm{NH}_{3}$ treatment as indicated by the broad N1s spectrum: the pyridinic nitrogen region (labelled as $\mathrm{N} 1$, at about $398.5 \mathrm{eV}$ ); the $\mathrm{N}-\mathrm{H}$ bond region (labelled as $\mathrm{N} 2$, at about $399.2 \mathrm{eV}$ ) includes amide and amine moieties; the pyrrol region (labelled as $\mathrm{N} 3$, at about $400.1 \mathrm{eV}$ ) composes the contribution of pyridone, lactame and pyrrol functional groups; labelled as $\mathrm{N} 4$ at $401-403 \mathrm{eV}$ is the quaternary nitrogen. The thermally most stable $\mathrm{N}$ species contributes to this last component. ${ }^{[36]}$ Furthermore, a peak with a binding energy shift of $+5 \mathrm{eV}$ compared to pyridine is assigned to pyridine oxide.

At $473 \mathrm{~K}$ treatment temperature, $\mathrm{CNH}$ aliphatic moieties are prevalent (N2 and N3 components), while at $873 \mathrm{~K}$, substitutional $\mathrm{N}$ i.e. pyridine-like $\mathrm{N}$ is enhanced (N1) as well as the most thermally stable $\mathrm{N} 4$ components.

The N1s spectra after the sequential $\mathrm{Au}$ and $\mathrm{Pd}$ immobilizations are reported in Figure 6B. While for the NCNT_473 the distribution of $\mathrm{N}$ species remains unaffected by the metal immobilization (Figure 6B top), the N1s line-shape of the NCNT 873 is modified after the immobilization: the relative abundance of the $\mathrm{N} 1$ components decreases and the N2 component increases (Figure 6B bottom). One may conclude that while on the $\mathrm{Pd} 873$ the interaction of metal species occurs through the $\mathrm{N}$ atoms, in the case of the $\mathrm{Pd} 4473$, the interaction occurs through the $\mathrm{O}$ atoms at the carbon surface. Surprisingly, exposure to the reactive atmosphere for $12 \mathrm{~min}$ (i.e. $\mathrm{H}_{2} \mathrm{O}_{2}$ ) did not significantly change qualitatively and quantitatively the nitrogen species distribution (Table S1). This is observed also for the monometallic samples. ${ }^{[3]}$ It is concluded that the nitrogen species are either too stable for oxidation and with respect to the aggressive nature of some oxygen intermediates are not accessible for oxidation as they are involved in binding the metallic species.

Nature of the Pd species on NCNT by XPS
The bonding state of $\mathrm{Pd}$ was investigated by high resolution X-ray photoelectron spectroscopy. Figure 7 shows the fitted Pd3d core level spectra for the fresh and used samples after 12 minutes of reaction.

For the fresh samples, the feature below $336 \mathrm{eV}$ can be fitted with only one Doniach-Sunjic component assigned as $\mathrm{Pd}(\mathrm{I})$ (magenta). To fit the region of the spectrum above 336 $\mathrm{eV}$, it is necessary to use two components with a GaussLorentz peak profile that are indicated as $\mathrm{Pd}(\mathrm{II})$ in blue and $\mathrm{Pd}(\mathrm{III})$ in ocher yellow.

In the case of monometallic samples, the $\mathrm{BE}$ of the $\mathrm{Pd}(\mathrm{I})$ is found at around $335.55 \pm 0.05 \mathrm{eV}$ and the FWHM is $1.4 \mathrm{eV}$. This value is slightly shifted to higher $\mathrm{BE}$ and broader with respect to the reported bulk metallic $\mathrm{Pd}$ phase $(335 \mathrm{eV})$ for $\mathrm{Pd}$ foil, ${ }^{[15-17,37]}$ clusters ${ }^{[38-39]}$ or single crystal. ${ }^{[40-43]}$ Broadening and shift to higher BE was reported as an initial state effect due to charge transfer from $\mathrm{Pd}$ to hosting impurities (i.e. $\mathrm{C}$ from the support or overlayer) ${ }^{[40-45,46-48]}$ or alloying. ${ }^{[38-39,46]} \mathrm{A}$ particles size effect due to final-state screening of core holes would occur, should the Pd particles not be electronically connected to the semimetal carbon. ${ }^{[43-44,47]} \mathrm{A}$ similar shift of the Pd3d core level was reported for Pd nanoparticles in the range of 3-4 nm. ${ }^{[49]}$ The FWHM of the Pd3d5/2 peak reported in literature was $1.26 \mathrm{eV}$ for nanoparticles smaller than $1 \mathrm{~nm}$ deposited on HOPG. ${ }^{[49]}$ We can thus assign the $\mathrm{Pd}(\mathrm{I})$ species to a distribution of monometallic nanoparticles with a varying extent of interaction with the carbon surface.

In the case of the bimetallic samples, the Au4f spectra are well fitted with only one component and as no significant changes were observed in the Au4f spectra among the samples, those are not reported.

The single Au4f7/2 peak is found at $83.8 \mathrm{eV}$ (FWHM $0.8 \mathrm{eV}$ ) and the $\mathrm{Pd} 3 \mathrm{~d} 5 / 2$ is observed at $335.1 \mathrm{eV} \pm 0.05 \mathrm{eV}$ (FWHM $1.2 \mathrm{eV}$ ). A similar Au4f binding energy was reported for clean $\mathrm{Au}$ foil ${ }^{[37,49]}$ while alloying was reported to cause a shift to lower binding energy in the range of $0.2-0.7 \mathrm{eV} .{ }^{[46]} \mathrm{A}$ downward shift of $\mathrm{Pd} 3 \mathrm{~d}$ positions due to alloying was reported of about $0.2 \mathrm{eV} .{ }^{[37]}$ We did not observe such alloy formation effects as the single Au4f line is well in agreement with monometallic gold. The effect of gold on the electronic 


\section{ChemSusChem}

\section{Full Papers \\ wvww.chemsuschem.org}

structure of $\mathrm{Pd}$ is however more obvious in the Pd3d line where the observed downward shift of around $0.4 \mathrm{eV}$ indicates inter-diffusion of atomic Pd into the Au. The absolute BE for the $\mathrm{Pd} 3 \mathrm{~d}$ line in the PdAu nanoparticles is slightly higher than the reported value. ${ }^{[37]}$

The bimetallic particles are homogeneous and only weakly interacting with the support as also suggested from the TEM observations. They may be considered as gold diluted with $\mathrm{Pd}$ atoms. The monometallic particles are in part more strongly interacting with the support as also seen by the raft structures in the TEM. Less strongly interacting species with a distribution of sizes across the limits for finale state effects (a few $\mathrm{nm}$ ) exist in addition being also well compatible with the TEM observations.

The Pd (II) and Pd(III) species are found at $336.9 \pm 0.05 \mathrm{eV}$ and at $338 \pm 0.05 \mathrm{eV}$ with a FWHM of $1.6 \mathrm{eV}$ for all samples. These findings can be summarized as follows. To assign the chemical nature of $\mathrm{Pd}(\mathrm{II})$ and $\mathrm{Pd}(\mathrm{III})$, we first excluded the presence of differential charging by applying a bias according to the method proposed in. ${ }^{[50]}$ Depth profiling experiments (Figure $S 5 A-B$ ) reveal that the component $\mathrm{Pd}(\mathrm{II})$ is more abundant in the top nm layer (electrons KE $300 \mathrm{eV}$ ), whereas $\mathrm{Pd}(\mathrm{I})$ and $\mathrm{Pd}(\mathrm{III})$ are equally abundant in the $2.5 \mathrm{~nm}$ deeper layer.

The existence of surface oxides of $\mathrm{Pd}$ has been demonstrated in earlier studies ${ }^{[44,51,52]}$ and is thus likely to be relevant also here. A Pd 3d core-level shift due to $\mathrm{O}$ on $\mathrm{Pd}$ was found at $337 \mathrm{eV}$ for nanoparticles on HOPG ${ }^{[44]}$ and for $\mathrm{PdO}$, ${ }^{[51]}$ nanoparticles while from an in-situ study on $\operatorname{Pd}(111)$ and on a $\mathrm{Pd}$ foil an oxygen-induced component appears at $336.25 \mathrm{eV}$. ${ }^{[40-41]}$ In-situ studies on the interaction of $\mathrm{O}_{2}$ and $\mathrm{CO}^{[52]}$ with the Pd surface for large Pd nanoparticles (15 and $35 \mathrm{~nm}$ ) reported a PdC phase with a $+0.6 \mathrm{eV}$ chemical shift, while the $\mathrm{Pd}-\mathrm{O}$ phase gave rise to $\mathrm{a}+1.3 \mathrm{eV}$ shift in agreement with the observations on the single crystal. It may thus be concluded that sub-surface compounds of $\mathrm{C}$ and $\mathrm{O}$ with the $\mathrm{Pd}$ nanoparticles give rise to the spectral components that cannot be assigned to metallic species.

In order to further understand the nature of these species, we have carried out an in-situ temperature-programmed desorption (TPD) XPS experiment on the sample PdAu_473K* (Figure S5). This sample was chosen as it presents the largest abundance of the $\mathrm{Pd}$ (III) component. Annealing in UHV up to $523 \mathrm{~K}$ partly reduced the $\mathrm{Pd}(\mathrm{II})$ and at the same time the $\mathrm{C}-\mathrm{O}$ species in the $\mathrm{C} 1 \mathrm{~s}$ and the $\mathrm{O} 1 \mathrm{~s}$ spectra decreased suggesting that this component might be correlated with $\mathrm{O}$ species on the surface and in the near surface region. This assignment to sub-surface species is in-line with the increase of this species under oxygen at 523K (Figure S5D). Similarly, the reduction of the $\mathrm{Pd} \_873$ by $\mathrm{H}_{2}$ at $0.1 \mathrm{mbar}$ pressure reduces the abundance of these species (Fig. S6). The Pd(III) component decreases only slightly upon annealing at 523K. Changing from UHV to $\mathrm{O} 2$ atmosphere at $523 \mathrm{~K}$ results in a small change of the Pd(III) component.

Therefore we can assume that the $\mathrm{Pd}(\mathrm{I})$ species describes an electronically modified $\mathrm{Pd}$ by impurities from $\mathrm{C}$ support. $\mathrm{Pd}(\mathrm{II})$ arises from an electronically modified $\mathrm{Pd}$ metal form caused by the intercalation of oxygen in and underneath the surface.

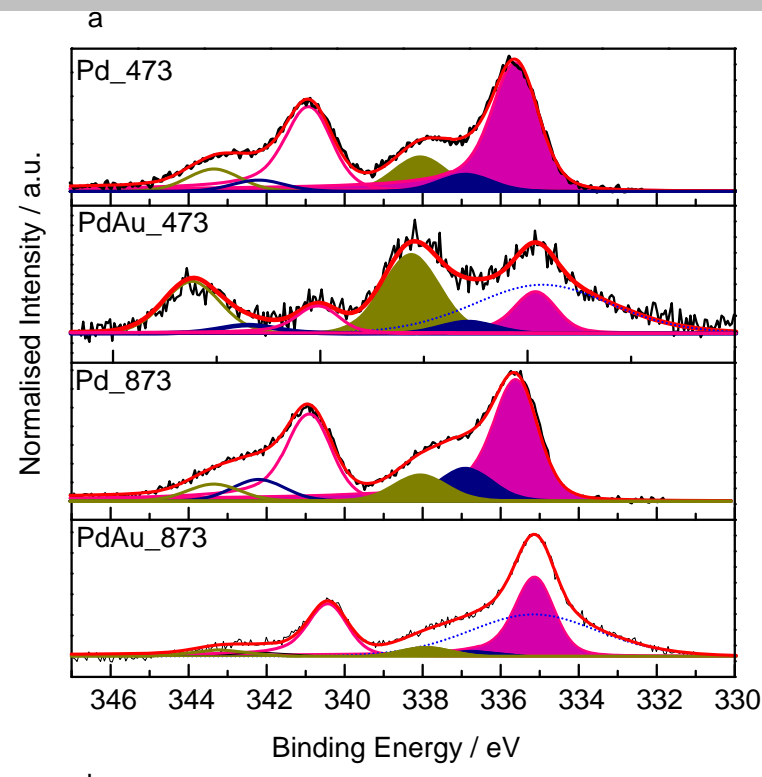

b

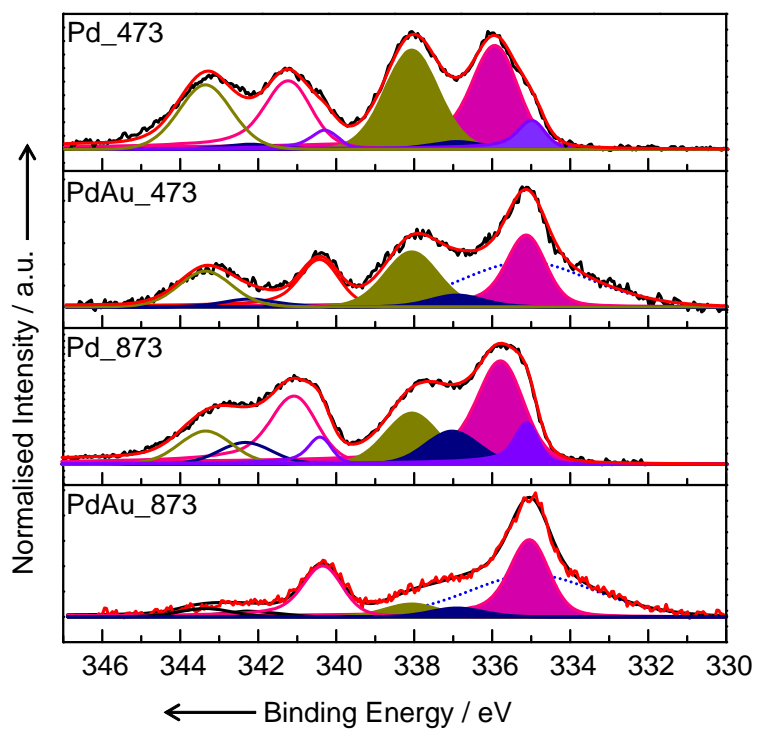

Figure 7. $P d 3 d X P$ core level spectra for the samples fresh $(A)$ and after 12 minutes of reaction (B) at $\mathrm{KE} 600 \mathrm{eV}$. Fitting: $\mathrm{Pd}(0)$ (violet peak); $\mathrm{Pd}(\mathrm{I})$ (magenta peak); Pd(II) (blue peak); Pd(III) (ocher yellow peak); dashed line in $\mathrm{PdAu} 873$ and $\mathrm{PdAu} 473$ is the $\mathrm{Au3d} \mathrm{d}^{5 / 2}$ peak.

The Pd (III) species is then assigned to divalent Pd. Similar chemical shifts as $\mathrm{Pd}(\mathrm{III})$ were found for very small $\mathrm{Pd}$ nanoparticles on alumina ${ }^{[53]}$ and iron oxide, ${ }^{[54]}$ for $\mathrm{Pd}\left(\mathrm{NH}_{3}\right)_{4} \mathrm{Cl}_{2}$ nanowires ${ }^{[55]}$, nitrogen-containing conjugated polymerpalladium systems ${ }^{[56]}$, and amino-functionalized MCM-41 supported $\mathrm{Pd}(\mathrm{II})$ complex ${ }^{[57]}$ and are attributed to $\mathrm{Pd}^{2+}$ bounded to different ligands $(\mathrm{Cl}, \mathrm{N}, \mathrm{O})$. Freund and co-workers [58] studied the deposition of $\mathrm{Pd}$ on $\mathrm{Fe}_{3} \mathrm{O}_{4}(111)$ from alkaline $\mathrm{Pd}^{2+}$ solution and showed that polynuclear $\mathrm{Pdn}$-hydroxo complexes are adsorbed on the carrier surface. The decomposition of the deposited precursor by annealing in vacuum was studied by XPS and showed a shift from $337.8 \mathrm{eV}$ to $335.9 \mathrm{eV}$ after drying at $390 \mathrm{~K}$ and to $335.4 \mathrm{eV}$ upon annealing to $600 \mathrm{~K}$, indicating the complete reduction of the divalent precursor to $\mathrm{Pd}^{0}$. As only traces of chloride were detected in our case we assign the Pd (III) species to a 
divalent oxy-hydroxo form of $\mathrm{Pd}$ in analogy to the reference experiment by Freund and coworkers.

\begin{tabular}{|c|c|c|c|c|c|c|c|c|}
\hline \multirow{2}{*}{$\begin{array}{l}\text { fresh } \\
\mathrm{KE} \\
{[\mathrm{eV}]}\end{array}$} & \multicolumn{2}{|c|}{ Pd_873 } & \multicolumn{2}{|c|}{$\mathrm{Pd} \_473$} & \multicolumn{2}{|c|}{$\mathrm{PdAu}$ _873 } & \multicolumn{2}{|c|}{ PdAu 473} \\
\hline & 150 & 600 & 150 & 600 & 150 & 600 & 150 & 600 \\
\hline $\mathrm{Pd}(\mathrm{I})$ & - & 0.76 & - & 0.79 & 0.78 & 0.75 & 0.37 & 0.34 \\
\hline $\mathrm{Pd}(\mathrm{II})$ & - & 0.13 & - & 0.07 & 0.10 & 0.11 & 0.16 & 0.08 \\
\hline $\mathrm{Pd}(\mathrm{III})$ & - & 0.11 & - & 0.14 & 0.12 & 0.14 & 0.47 & 0.57 \\
\hline $\mathrm{Pd}(0)$ & - & - & - & 0 & 0 & 0 & 0 & 0 \\
\hline \multicolumn{3}{|c|}{$\begin{array}{ll}12 & \\
\min & \mathrm{Pd} \_873 \mathrm{u} \\
\end{array}$} & \multicolumn{2}{|c|}{$\mathrm{Pd} \_473 \mathrm{u}$} & \multicolumn{2}{|c|}{ PdAu_873u } & \multicolumn{2}{|c|}{$\mathrm{PdAu} 473 \mathrm{u}$} \\
\hline $\operatorname{Pd}(\mathrm{I})$ & 0.64 & 0.58 & 0.52 & 0.46 & 0.77 & 0.77 & 0.51 & 0.51 \\
\hline $\mathrm{Pd}(\mathrm{II})$ & 0.22 & 0.14 & 0.10 & 0.03 & 0.11 & 0.12 & 0.18 & 0.14 \\
\hline $\mathrm{Pd}(\mathrm{III})$ & 0.14 & 0.19 & 0.38 & 0.33 & 0.12 & 0.11 & 0.31 & 0.35 \\
\hline $\operatorname{Pd}(0)$ & 0 & 0.09 & 0 & 0.18 & 0 & 0 & 0 & 0 \\
\hline
\end{tabular}

The Pd3d fitting model presented in this work discriminates between sub-species represented in the $P d(I)$; these are $P d(0)$ species in a heteroatomic bonding environment such as in strong interaction with the support or next to the Au matrix. The varying FWHM is taken as a descriptor for the heterogeneity of the chemical environment as well as of the particles size.

The $\mathrm{Pd}(\mathrm{II})$ component is due to Pd metal modified by oxygen atoms bound to the surface or dissolved sub-surface.

The $\mathrm{Pd}(\mathrm{III})$ contribution arises from divalent polynuclear $\mathrm{Pd}_{n}$-hydroxo complexes formed from the interaction of the $\mathrm{Pd}$ salt precursor with the hydrophilic carbon surface or resulting in the used samples from dissolution and re-precipitation. The addition of $\mathrm{NaBH}_{4}$ to the deposited $\mathrm{Pd}$ compound on the carbon surface did not completely reduce the precursor giving an estimate about the strength of the interaction of the $\mathrm{Pd}$ precursor with the functionalized carbon surface.

The 01s spectra for these samples are composed of the overlapping oxygen species of the PVA, the NCNT, the contribution of $\mathrm{Pd}-\mathrm{O}$ species, and the $\mathrm{Pd} 3 p$ core level. For this reason the comparative analysis between $\mathrm{Pd} 3 \mathrm{~d}$ and $\mathrm{O} 1 \mathrm{~s}$ is not attempted here.

\section{Distribution of Pd species as function of carbon surface chemistry}

The relative distribution of the $\mathrm{Pd}$ components varies among the samples and is summarized in Table 4.

PdAu_873 presents the most homogeneous Pd chemical bonding states as the spectrum is dominated by the $\operatorname{Pd}(\mathrm{I})$ peak; Additionally, the distribution of $\mathrm{Pd}$ species is similar after 12 min of reaction. Consistently, a homogeneous distribution of chemisorption sites for $\mathrm{CO}$ is observed on this sample by microcalorimetry (Fig. 8). The heat of $\mathrm{CO}$ chemisorption of this species is close to the value measured for a reduced $\mathrm{Pd}$ surface (Fig. 8B).

PdAu_473 is characterized by a higher amount of Pd(III) than present in PdAu_873. This is consistent with EDX mapping identifying $\mathrm{Pd}$ in two different environments (Fig.3C$\mathrm{E}$ ): $\mathrm{Pd}$ at the $\mathrm{C}$ surface (most of $\mathrm{Pd}(\mathrm{III})$ and Pd alloyed into the $\mathrm{Au}$ nanoparticles $(\operatorname{Pd}(\mathrm{I}))$. After 12 minutes of reaction the relative amount of $\mathrm{Pd}(\mathrm{III})$ undergoes a reduction and the relative amount of $\mathrm{Pd}(\mathrm{I})$ increases. With the additional information from XPS we assign the atoms on the Au particles in the fresh PdAu_473 in Figure $3 \mathrm{~B}$ to precursor Pd (III) components which convert to $\mathrm{Pd}(\mathrm{I})$ and interdiffuse as atoms into the $\mathrm{Au}$ nanoparticles to form $\mathrm{Pd}-\mathrm{Au}$ species. The comparison between the TEM image of PdAu_873 (Figure 4A) and the Pd3d spectrum suggests that the small amount of $\mathrm{Pd}(\mathrm{II})$ component in the bimetallic samples accounts for $\mathrm{Pd}$ nanoparticles in the observed raft-like morphology: such $\mathrm{Pd}$ species are strongly bound to the support and experience thus a shift comparable to that of a $\mathrm{O}$ sub-surface compound. The $\mathrm{Pd}(\mathrm{II})$ component is more abundant in the most surface sensitive measurements. The ratio $\mathrm{Pd}(\mathrm{II}) / \mathrm{Pd}(\mathrm{I})$ is thus taken as a measure of the particle morphology indicating a varying contribution of the strongly bound species in the different samples.

The monometallic samples exhibit after 12 min of reaction an additional contribution in the $\mathrm{Pd} 3 \mathrm{~d}^{5 / 2}$ spectrum as indicated by the line broadening of the $\mathrm{Pd}$ (I) component (violet contribution). This additional peak at $335.1 \mathrm{eV}$ is attributed to bulk metallic $\mathrm{Pd}$. This is in line with the sintering observed by TEM (Figure 4). The correct fitting of this peak requires a shift of the $\mathrm{Pd}(\mathrm{I})$ component to $0.2 \mathrm{eV}$ higher $\mathrm{BE}$. This indicates that the $\mathrm{Pd}(\mathrm{I})$ component is composed by two contributions: those $\mathrm{Pd}$ species whose chemical environment is closer to the Pd0 bulk state (less electronically modified by the $C$ support and hence lower $\mathrm{BE}$ ) undergo sintering and give rise to the $\operatorname{Pd}(0)$ component, while the highly dispersed nanoparticles are those which account for the remaining component shifted apparently to $0.2 \mathrm{eV}$ higher $\mathrm{BE}$.

The distribution of the components is sensitive to the chemistry of the support (Figure 6). For instance in both fresh NCNT_473 samples the component $\mathrm{Pd}(\mathrm{III})$ is more abundant than in the corresponding NCNT_873 materials. The impact of the reaction is also observed in the increase of the $\mathrm{Pd}(\mathrm{III})$ species for the Pd_473 and to a lesser extend Pd_873. This is the consequence of extended dissolution and re-precipitation of Pd on the NCNT_473 support as compared to the support modified at $873 \mathrm{~K}$.

Besides re-deposited divalent $\mathrm{Pd}$ species some of the $\mathrm{Pd}(\mathrm{III})$ species is remaining unreduced from its synthesis on the NCNT_473 support. The stabilization of $\mathrm{Pd}^{2+}$ species must thus be favoured by the surface chemistry of the support during impregnation. The immobilization of $\mathrm{Pd}$ on $\mathrm{C}$ supports was reviewed extensively. ${ }^{[59]}$ Incipient wetness impregnation of $\mathrm{H}_{2} \mathrm{PdCl}_{4}$ on carbon results in a high $\mathrm{Pd}^{2+} / \mathrm{Pd}^{0}$ ratio. High $\mathrm{Pd}^{2+}$ is favored when ligands that decrease the redox potential $\mathrm{E}^{0} \mathrm{Pd}^{2+} / \mathrm{Pd}$ value are present, such as oxidants $\left(\mathrm{H}_{2} \mathrm{O}_{2}\right)$ created by the hydrolysis of basic oxygen functional groups in the presence of gas-phase oxygen during the impregnation. ${ }^{[59]}$ At the low metal loading it may well be assumed that the nitrogen functional groups at the carbon surface contribute to the stabilization of divalent $\mathrm{Pd}$ in the form of $\mathrm{Pd}-\mathrm{N}$ complex formation. This is more likely to occur on the surface of the NCNT_473 support than on the NCNT_873 material as seen from the XPS data in Figure 6 . The predominant heterocyclic nature of nitrogen in the NCNT_873 sample prevents their modification by hydrogen during catalysis. $\mathrm{Pd}$ species anchored to such sites should remain unaffected. On the NCNT_473 surface the nitrogen is predominantly present in structures substituting $\mathrm{C}-\mathrm{H}$ groups. These structures are more 


\section{ChemSusChem}

\section{Full Papers \\ www.chemsuschem.org}

susceptible to reduction by activated hydrogen spilling over from the anchored $\mathrm{Pd}$ species. It is thus to be expected that the stabilizing function of surface functional groups on NCNT_473 will not withstand the reaction conditions and hence will not prevent aggregation of Pd. This argument holds also for the modification of the Pd (II) species. We conclude that neither the amount of Pd nor the abundance of surface functional groups alone will determine the efficiency of the catalysts but only the combination of non-reducible surface functional groups with little enough Pd to prevent the formation of non-wetting metal nanostructures.

\section{Microcalorimetry of CO chemisorption}

In order to determine the Pd metal surface as upper limit for the number of active sites, $\mathrm{CO}$ chemisorption was carried out on the used samples after 12 min of $\mathrm{H}_{2} \mathrm{O}_{2}$ synthesis by means of microcalorimetry. Such information is of particular relevance with samples that are partly still covered by the protective PVA over layer preventing geometric considerations as basis for estimating the reactive surface area. In addition to the standard volumetric method for the determination of the specific surface area, microcalorimetry can give information about the distribution of metal sites with varying local electronic structure that is controlling the differential heat of chemisorption. From the preceding analysis it is expected that such sites will exist following the analysis of the $\operatorname{Pd}(I)$ and $\mathrm{Pd}$ (II) species that should give rise to differences in their heat of $\mathrm{CO}$ chemisorption.

Figure 8A displays differential heats of $\mathrm{CO}$ adsorption over the four samples as a function of the amount of $\mathrm{CO}$ adsorbed. The heat of physisorption of CO on $\mathrm{Pd}$ is $40 \mathrm{~kJ} / \mathrm{mol}$. It is thus obvious that all samples exhibit substantial amounts of sites chemisorbing $\mathrm{CO}$ in various local electronic structures. It is further obvious that the samples modified by gold exhibit a similar energetic distribution whereas the monometallic samples behave quite differently.

The amount of adsorbed $\mathrm{CO}$ on Pd-free Au_873u was negligible. Taking into account the unmodified electronic structure of gold according to our XPS results we can assume that for the bimetallic samples the adsorption occurs selectively on the $\mathrm{Pd}$. $\mathrm{CO}$ adsorption on $\mathrm{PdAu} 873$ produces a differential heat profile characterized by a plateau at $\sim 76 \mathrm{~kJ} / \mathrm{mol}$. This indicates that the catalyst exhibits approximately $1 \mu \mathrm{mol} / \mathrm{g}$ energetically uniform sites. A similar heat of chemisorption was found for the PdAu_473 $(79 \mathrm{~kJ} / \mathrm{mol})$ but the amount of chemisorption sites is much smaller, in agreement with the lower abundance of $\mathrm{Pd}(\mathrm{I})$ for this sample. In agreement with the XPS observations, this indicates that the catalysts are very homogeneous in the electronic structure of their $\mathrm{Pd}$ nanoparticles. This corresponds also to high selectivity in the partial hydrogenation observed for these catalysts (see Table 1).

The Pd_873, and Pd_473 exhibit a differential heat profile that shows an initial heat value of 67 and $96 \mathrm{~kJ} / \mathrm{mol}$, respectively. The differential heat of chemisorption decreases for both samples with increasing coverage indicating that the surface metal adsorption sites are energetically heterogeneously distributed. Comparing the data in Figure 8 with those of the catalytic performance presented in Figures 1 and 2 allows concluding that the number or active sites for oxygen hydrogenation is much smaller than the number of $\mathrm{Pd}$
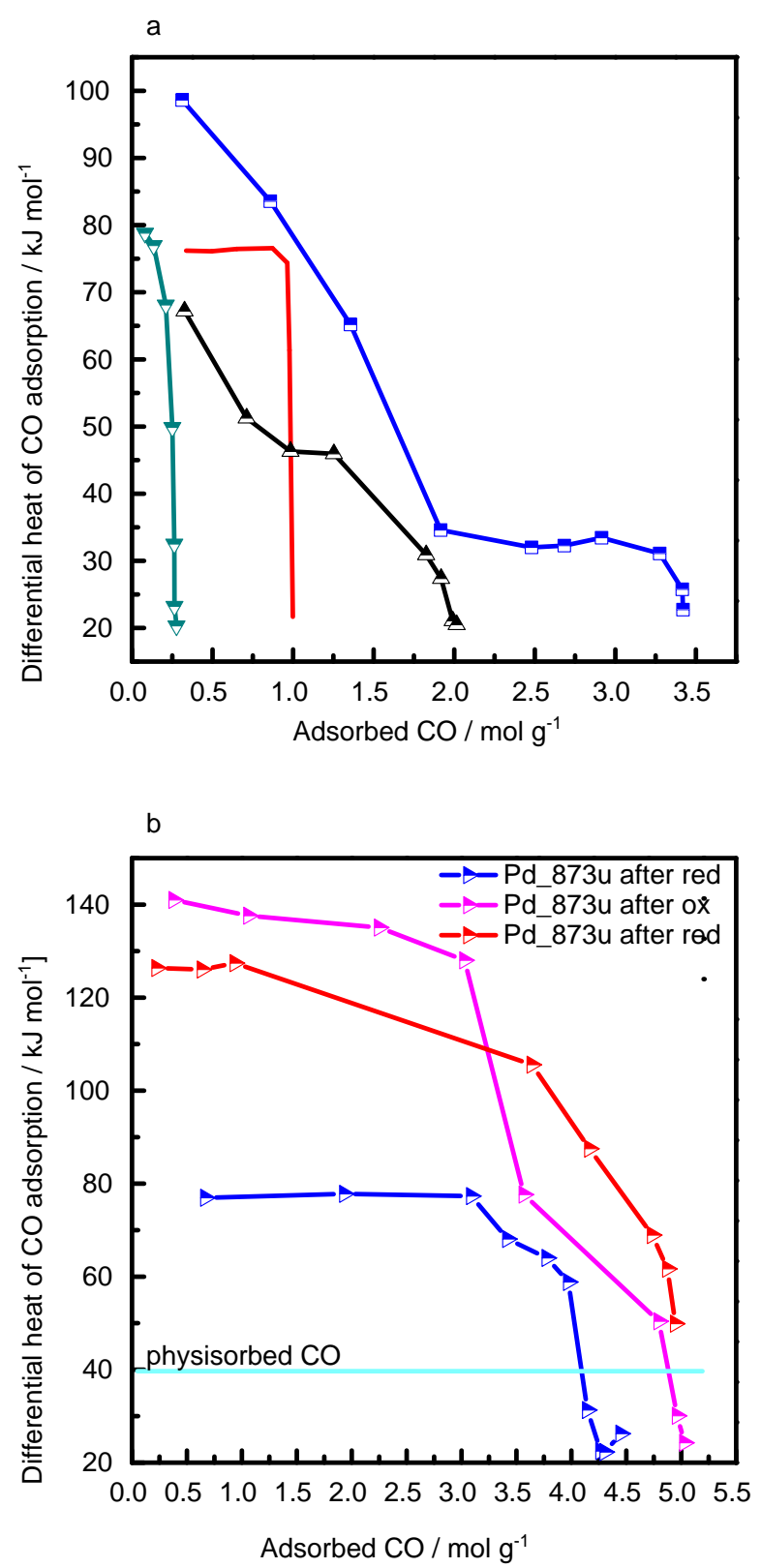

Figure 8. (A) Differential heat of $\mathrm{CO}$ chemisorption vs. amount of $\mathrm{CO}$ uptake for Pd_873u (black curve); Pd_473u (blue curve); PdAu_873K (red curve); $\mathrm{PdAu} 473 \mathrm{~K}$ (green curve). (B) Differential heat of $\mathrm{CO}^{-}$chemisorption vs. amount of $\mathrm{CO}$ uptake for $\mathrm{Pd} \_873 \mathrm{u}$ : after reduction in $\mathrm{H}_{2}$ (blue curve) at 1 bar and $373 \mathrm{~K}$; after the $\mathrm{CO}$ desorption from the $1^{\text {st }}$ cycle and oxidation in $\mathrm{O}_{2}$ at 1 bar and $373 \mathrm{~K}$ (magenta curve); after $\mathrm{CO}$ desorption from the $3^{\text {rd }}$ step and reduction in $\mathrm{H}_{2}$ (red curve) at 1 bar and $373 \mathrm{~K}$.

sites detected by $\mathrm{CO}$ chemisorption. From the differences in selectivity it may be concluded that the desirable sites for selective oxygen hydrogenation are not those with maximum heat of chemsiorption for $\mathrm{CO}$. One may further conclude that the activity is related to the energetic position and the width of a plateau in the $\mathrm{CO}$ chemisorption curve between 80 and 50 $\mathrm{kJ} / \mathrm{mol}$ and the unselective water formation may be related to the abundance of species with high or changing heats of 
adsorption for CO. In correlation with the Pd XPS data it is possible to assign the species that give rise to a plateau to the $\mathrm{Pd}$ (II) form. The modification with gold seems to substantially increase the heat of chemisorption at the uniform sites assigned as relevant reactive sites for selective hydrogenation of activated oxygen $(\mathrm{Pd}(\mathrm{I}))$. High values of heats of adsorption and values close to the physisorption limits may be assigned to pure metallic Pd particles with irregular surface sites and with passivating overlayers.

\begin{tabular}{|c|c|c|c|c|c|}
\hline Samples ${ }^{[a]}$ & $\begin{array}{c}\mathrm{S}_{\mathrm{co}}^{[\mathrm{bb}]} \\
{\left[\mathrm{m}^{2} / \mathrm{g}\right]}\end{array}$ & $\begin{array}{c}\mathrm{S}_{\mathrm{th}}^{[\mathrm{cc}]} \\
{\left[\mathrm{m}^{2} / \mathrm{g}\right]}\end{array}$ & $\begin{array}{l}\mathrm{dp}^{[\mathrm{dd}]} \\
{[\mathrm{nm}]}\end{array}$ & $\begin{array}{c}\text { Initial heat of } \\
\text { chemisorption } \\
{[\mathrm{kJ} / \mathrm{mol}]}\end{array}$ & $\operatorname{Pd}[\%]^{[e]}$ \\
\hline Pd_873u & 0.20 & 1.65 & $1.9 \pm 1.5$ & 67 & $1.60 \pm 0.06$ \\
\hline Pd_473u & 0.34 & 0.75 & $2.9 \pm 0.9$ & 96 & $1.48 \pm 0.10$ \\
\hline PdAū_873u & 0.10 & 0.55 & $3.8 \pm 0.9$ & 76 & $0.70 \pm 0.07$ \\
\hline PdAu_473u & 0.03 & 0.55 & $3.8 \pm 1.5$ & 79 & $0.50 \pm 0.05$ \\
\hline
\end{tabular}

[a] after $12 \mathrm{~min}$ of reaction; [b] monolayer capacity of $\mathrm{CO}$ adsorption at $323 \mathrm{~K}$ estimated by the Langmuir model; [c] surface area estimated by STEM assuming semispherical exposure of particles; [d] average size of particles determined by STEM; [e] Atomic\% Pd abundance by XPS at $600 \mathrm{eV}$.

This assignment is in contrast with selected literature observations. Differential heats of $\mathrm{CO}$ chemisorption on carbon-supported $\mathrm{Pd}{ }^{[60]}$ are in the range of $70-90 \mathrm{~kJ} / \mathrm{mol}$, which is lower than the corresponding values of $\mathrm{Pd}$ supported on oxide $71-150 \mathrm{~kJ} / \mathrm{mol}$ catalysts. ${ }^{[61-62]}$ Recently, ${ }^{[63-64]}$ the particle size dependence of the heat of $\mathrm{CO}$ adsorption on $\mathrm{Pd}$ nanoclusters from 1.8 to $8 \mathrm{~nm}$ was investigated by singlecrystal adsorption microcalorimetry. In contrast to early literature, ${ }^{[65-66]}$ the adsorption enthalpy of carbon monoxide decreases with decreasing particles size by about $20 \mathrm{~kJ} \mathrm{~mol}-1$ from about $145 \mathrm{~kJ} / \mathrm{mol}$ for single crystals to $120 \mathrm{~kJ} / \mathrm{mol}$ for initial coverages and down to $80 \mathrm{~kJ} / \mathrm{mol}$ for saturation coverage independent of particle size. These reference observations indicate that the catalysts in this study exhibit typically lower heats of adsorption (see Table 5 and Figure $8 \mathrm{~A}$ ) than pure $\mathrm{Pd}$ systems. Both, Au atoms and sub-surface species are made responsible for this trend. The observation supports the view that lowering of chemisorption energy of oxygen (for which we take the CO adsorption as proxy) is a tool for controlling the selectivity of the reaction.

To determine the reactive surface area of the catalysts, fitting of the $\mathrm{CO}$ adsorption isotherms to the Langmuir model was performed for all 4 samples. ${ }^{[67]}$ Based on the determined saturation concentration the accessible Pd surface area was calculated with an assumed adsorption stoichiometry for $\mathrm{Pd}: \mathrm{CO}=1: 1$ and a cross-sectional area of the CO molecule occupying $\sim 16.2 \AA^{2} .{ }^{[67]}$ The results are given in Table 5 . The specific metal surface area increased in the order of $\mathrm{PdAu} 473 \mathrm{u}\left(0.027 \mathrm{~m}^{2} / \mathrm{g}\right), \mathrm{PdAu} \_873 \mathrm{u}\left(0.103 \mathrm{~m}^{2} / \mathrm{g}\right), \mathrm{Pd} \_873 \mathrm{u}$ $\left(0.196 \mathrm{~m}^{2} / \mathrm{g}\right)$ and Pd_473u $\left(0.337 \mathrm{~m}^{2} / \mathrm{g}\right)$ which is not in line with the metal loading.

The surface area determined by $\mathrm{CO}$ chemisorption is much smaller than the expected surface area from analyzing the particle geometry as semi-spheres weighted with the particles size distribution (Table 5). In particular, the exposed surface area sensed by chemisorption is higher for the Pd_473u than the $\mathrm{Pd} \_873 \mathrm{u}$, which is at variance with the average particles size trend. This is partly explained by the coverage of the surface with impurities (i.e. PVA coverage) which seems lower on the Pd_473u than on the Pd_873u.

Another explanation for the small values of the reactive surface area may be found in the redox chemistry of the Pd particles where overlayers or sub-surface species may reduce the heat of chemisorption of $\mathrm{CO}$ such that at $313 \mathrm{~K}$ adsorption temperature not all $\mathrm{Pd}$ sites would be covered by $\mathrm{CO}$. A series of reference experiments for the differential heat of $\mathrm{CO}$ chemisorption on reduced $\mathrm{Pd}$ and on oxidized $\mathrm{Pd}$ were obtained for the Pd_873u sample. It was subjected to cycles of reduction, $\mathrm{CO}$ chemisorption and oxidation and $\mathrm{CO}$ chemisorption. The results of these investigations are reported in Figure 8B.

The CO chemisorption on the reduced $\mathrm{Pd} 873 \mathrm{u}$ is completely reversible (integral heat ads. $\approx$ integral heat des.) and shows the same plateau at the same differential heat value as that observed for the PdAu_873 (76 kJ/mol). After reduction the sites are energetically homogeneous and therefore we can consider this value as the chemisorption of $\mathrm{CO}$ on modified $\mathrm{Pd}$ being beneficial for hydrogen peroxide synthesis. The value is about half of the heat of chemisorption of $\mathrm{CO}$ on clean genuine $\mathrm{Pd}$ metal indicating a substantial modification of the electronic structure as also found with the shift of $\mathrm{Pd}(\mathrm{I})$ in XPS. The surface area after the reduction is much higher and $0.40 \mathrm{~m}^{2} / \mathrm{g}$ indicating the enlargement of the exposed $\mathrm{Pd}$ domain probably due to the loss of adsorbates. After $\mathrm{CO}$ desorption, the surface of $\mathrm{Pd} \_873 \mathrm{u}$ was oxidized at 1 bar and $373 \mathrm{~K}$. This treatment leads to a much higher differential heat of CO adsorption, above $140 \mathrm{~kJ} / \mathrm{mol}$, with a plateau. The $\mathrm{CO}$ chemisorption on the oxidized surface however contains an irreversible part (integral heat ads. > integral heat des.). In this state the Pd was oxidized to PdO that decomposed upon evacuation. It exhibits the character of large metallic particles. Some of the Pd contains still oxygen that is reduced by the $\mathrm{CO}$ probe gas accounting so for the partial irreversibility. Further successive reduction of this sample at 1 bar $\mathrm{H}_{2}$ and $373 \mathrm{~K}$ did not lead to the initial differential heat value of $\mathrm{CO}$ chemisorption of the reduced $\mathrm{Pd} \_873 \mathrm{u}$, but an intermediate value between the 1st reduction cycle and the oxidation cycle. This and the absence of a defined plateau is indication for a re-structuring of the $\mathrm{Pd}$ creating inhomogeneous sites either by re-dispersion and/or by partial restoring of sub-surface compounds.

Microcalorimetry was used to probe the structural dynamics of the Pd nanoparticles by a quantitative integral method. Clear evidence for the response of the chemisorption properties on the environment of the Pd particles was found. After calcination and vacuum decomposition of the oxide a metallic state was found that is similar to model nanoparticles prepared by physical vapour deposition. Reductive treatment destroyed the structural homogeneity of the adsorption sites and gives rise to weaker chemisorption. Although the atomic details of the dynamics remain in this experiment elusive we conclude from the similar total $\mathrm{CO}$ uptake seen in Figure 8B that once all remaining PVA over layers are removed the total number of sites remains constant indicating geometric stability of the Pd. The ease with which selective (sub-surface modified) and unselective (pure metallic) states interchange with a change of the reaction environment indicates the enormous relevance of transport limitations in a catalytic 


\section{ChemSusChem}

\section{Full Papers}

operation: local variations in chemical potential can instantaneously switch the catalyst from selective to unselective and vice versa. This fundamentally interesting property is highly undesirable in practical exploitation of the reaction.

\section{Nanostructure/activity correlation}

The catalyst characterization is discussed with the aim to describe material aspects of the selective and unselective episodes in the catalytic performance of $\mathrm{H}_{2} \mathrm{O}_{2}$ synthesis in the semi-batch mode of operation. A characteristic change from selective to unselective operation occurs as a collective modification of the whole catalyst mass for each sample at a different time on stream: around 10 min for $\mathrm{Pd} 4473,50 \mathrm{~min}$ for the Pd_873, $75 \mathrm{~min}$ for $\mathrm{PdAu} 8873$ and $90 \mathrm{~min}$ for the $\mathrm{PdAu}$ 473. The data collected allow an insight into the behaviour of $\mathrm{Pd}$ in the $\mathrm{H}_{2} \mathrm{O}_{2}$ synthesis and may facilitate the identification of a strategy to obtain stable and active catalysts.

The TEM analysis, XPS and microcalorimetry reveal in general heterogeneity of the nature of the $\mathrm{Pd}$ species and considerable variations in the species distribution between the samples. The $\mathrm{Pd}$ species are consistently described by 4 distinguishable forms of $\mathrm{Pd}$ in the high resolution $\mathrm{Pd} 3 \mathrm{~d}$ core level XP spectrum: $\mathrm{Pd}(\mathrm{I}), \mathrm{Pd}(\mathrm{II}), \mathrm{Pd}(\mathrm{III})$ and $\mathrm{Pd}(0)$.

The sintered particles of several $\mathrm{nm}$ in size observed in the monometallic samples after 12 min of reaction $(\mathrm{Pd}(0)$ in Figure 7) exhibit the same $B E$ as $P d$ in the bimetallic sample (335.1 $\mathrm{eV}$ ). This value indicates metallic bonding in a bulk-like metallic state.

The smaller particles with a radius around 1-2 $\mathrm{nm}$ observed in the monometallic samples give rise to the $\mathrm{Pd}(\mathrm{I})$ component and to the $\mathrm{Pd}(\mathrm{II})$ components in XPS. Both are electronically modified Pd metal forms affected by the interaction with strong anchoring sites of the $\mathrm{C}$ support and by sub-surface compound formation with light atoms such as $\mathrm{H}, \mathrm{C}, \mathrm{O}$ respectively.

The $\mathrm{Pd}(\mathrm{III})$ signal is attributed to ionic $\mathrm{Pd}^{2+}$ species at the hydrophilic domain of the carbon surface. In HAADF-STEM images they are detected as very small clusters or monoatomically dispersed $\mathrm{Pd}$ with a hazy contrast.

We discuss now the Pd3d components in conjunction with the catalytic performance. It is convenient to consider first the sample PdAu_873u which is characterized by the most homogeneous chemical state. The $\mathrm{H}_{2} \mathrm{O}_{2}$ yield after 12 min is low with respect to the monometallic $\mathrm{Pd} \_873 \mathrm{u}$ but the $\mathrm{Pd} 3 \mathrm{~d}$ spectra of the PdAu_873u represent the catalyst in its selective state (Table 1). The sample contains predominantly the $\operatorname{Pd}(I)$ species modified in its electronic structure by gold atoms. Small amounts of $\mathrm{Pd}(\mathrm{II})$ and $\mathrm{Pd}(\mathrm{III})$ species are also present. We exclude the $\mathrm{Pd}(\mathrm{III})$ component from being beneficial for selective hydrogenation by comparing the XPS data to those of $\mathrm{PdAu} 473 \mathrm{u}$ revealing poor catalytic activity. This sample is mainly composed by cationic Pd dispersed on the NCNT surface indicating that this is not the desired species in agreement with the finding of Lunsford et al. ${ }^{[68]}$

The prominent candidate for the selective hydrogenation is thus the $\mathrm{Pd}(\mathrm{I})$ component representing electronically modified metal with the consequence of reduced adsorption energy for $\mathrm{CO}$ and likely also for oxygen. From Figure 1 we see that all samples need an activation period that is longer for the gold modified samples than for the monometallic samples. In addition we see that the unselective hydrogenation to water is a consecutive reaction as only after the $\mathrm{H}_{2} \mathrm{O}_{2}$ synthesis has started, water is being formed. Returning to the speciation of the active $\mathrm{Pd}$ we assign the electronically modified $\mathrm{Pd}$ to the selective reaction path and pure $\mathrm{Pd}$ to the unselective path. Unfortunately there seems a rapid transformation of some of the $\mathrm{Pd}(\mathrm{I})$ species into electronically normal $\mathrm{Pd}$ : this transformation is the consequence of the switching on of the non-selective hydrogenation. This is consistent with the dynamic study using microcalorimetry. The benefit of gold is to retain the predominant amount of $\mathrm{Pd}$ in the electronically modified state as no $\operatorname{Pd}(0)$ occurs here. Most useful for the desired reaction seem to be the $\operatorname{Pd}(\mathrm{II})$ species as they are stable and active and seem not to decompose during reaction.

The role of the PVA overlayer seems to be not only to prevent agglomeration of $\mathrm{Pd}$ paricles by preventing geometric contact but also to keep the Pd in the electronically modified state: the bonding of PVA to the surface is believed to modify the electronic structure of $\mathrm{Pd}$ in the same beneficial way as sub-surface compound formation or gold incorporation. The modification is to reduce the bond strength of oxygen preventing its dissociation without however preventing the dissociative binding of hydrogen.

An intermediate density of states at the Fermi level is the design target that was probed by the initial heat of $\mathrm{CO}$ chemisorption. The best catalyst $\left(\mathrm{Pd}_{-} 873\right)$ revealed a reduction of about half the bond strength of unmodified $\mathrm{Pd}$ for $\mathrm{CO}$ chemisorption indicating a substantial change in electronic structure of the Pd. The incorporation of gold atoms into Pd was not a strong enough modifier of the electronic structure. Its benefit as modifier is the inertness upon segregation: gold alone is a poor catalyst both for synthesis and for deep hydrogenation of $\mathrm{H}_{2} \mathrm{O}_{2}$.

The $\mathrm{Pd}(\mathrm{III})$ species increases in its abundance after the decomposition test and it is abundant in the unselective catalyst ( $\mathrm{Pd}$ _ 473). Literature reports show that $\mathrm{Pd}$ in a metallic state does not dissolve in solvents ${ }^{[69]}$ while it is only when the surface is coordinated to $\mathrm{O}$ or $\mathrm{OH}$ that the dissolution to $\mathrm{Pd}^{2+}$ can take place. The dissolution will be favored by acidic solutions (the reaction are carried out in $\mathrm{H}_{2} \mathrm{SO}_{4}$ to minimize the $\mathrm{H}_{2} \mathrm{O}_{2}$ decomposition) while the re-deposition of the $\mathrm{Pd}^{2+}$ complexes will occur at the hydrophilic sites on the carbon surface. We can assume that the re-deposition of $\mathrm{Pd}$ is the consequence of first a destruction of the $\mathrm{Pd}(\mathrm{I})$ sites followed by the dissolution of the resulting very small metallic units that deeply hydrogenate $\mathrm{H}_{2} \mathrm{O}_{2}$.

$\mathrm{Pd} \_873$ and $\mathrm{Pd}$ _473 are active catalysts but while after $12 \mathrm{~min}$ of reaction the former is selective, the latter shows much lower selectivity to $\mathrm{H}_{2} \mathrm{O}_{2}$. Both samples contain initially a similar distribution of $\mathrm{Pd}$ components in their XPS, but the impact of the reactive environment is different. As revealed by microscopy and XPS analysis, agglomeration occurred on both monometallic samples after $12 \mathrm{~min}$ of reaction and became significant after $3 \mathrm{~h}$ of reaction as shown by HAADF-STEM (Figure S3). A loss of the PVA shell due to oxidation during the reaction mobilizes the metal nanoparticles resulting in rapid agglomeration, ${ }^{[20]}$ except for few strongly bound nanoparticles detected as $\operatorname{Pd}(\mathrm{II})$. However, the catalyst $\mathrm{Pd} 873$ remains selective after agglomeration indicating the relative inefficiency of sintered particles in the deep hydrogenation, while the minority of stable small nanoparticles $(\operatorname{Pd}(\mathrm{II}))$ maintains high activity and selectivity. 
This difference in stability is traced back to a difference in the nitrogen doping of the support. The electron-donating functional complexes of the graphitic surface involving thermally stable $\mathrm{N}$ species ${ }^{[20]}$ on NCNT_873 allow for a strong metal support interaction. The particle size distribution by STEM as well as the initial differential heat of CO chemisorption reveal that the $\mathrm{Pd} \_873$ sample contains many of the smaller particles especially still after 12 min reaction. The NCNT_473 support containing more redox-sensitive $N$ functional groups cannot stabilize the $\operatorname{Pd}($ II) species during catalytic action due to oxidation of the functional groups. The resulting $-\mathrm{OH}$ groups are good stabilization sites for ionexchanging $\mathrm{Pd}(\mathrm{III})$ divalent species. Therefore the NCNT873 is the superior support as it provides, a ligand stabilization effect for electronically modified $\mathrm{Pd}$ with direct participation of specific substitutional $\mathrm{N}$ sites. ${ }^{[5]}$ It stabilizes a wetting $\mathrm{Pd}$ cluster species and with it the electronic state $\mathrm{Pd}^{\delta}$ that hinders the dissociative oxygen chemisorption. The modified Pd structure further limits the population of hydrogen in the subsurface region being responsible for the sintering and for unselective hydrogenation. ${ }^{[70]}$ Alloying has a similar effect on the selectivity than sub-surface chemistry. In the present catalysts the alloy systems exhibit a lower dispersion of the modified Pd (see Table 5) than the monometallic systems and are hence inferior in performance. A specific reduced activity with respect the sub-surface and support-modified systems is indicated by the difference in initial chemisorption energies for $\mathrm{CO}$ of the two classes of catalysts. The support may further play an additional role through $\mathrm{H}$ spill-over claimed to occur on hydrophobic carbon surfaces. ${ }^{[71-72]}$ This would be consistent with the improved activity of the NCNT_873 samples but our results do not confirm this mechanism. The equal and immediate activity in over-hydrogenation of $\mathrm{H}_{2} \mathrm{O}_{2}$ for all catalysts reported in Figure $1 \mathrm{C}$ rather excludes the notion that activated hydrogen would be a limiting factor in the selective hydrogenation of oxygen.

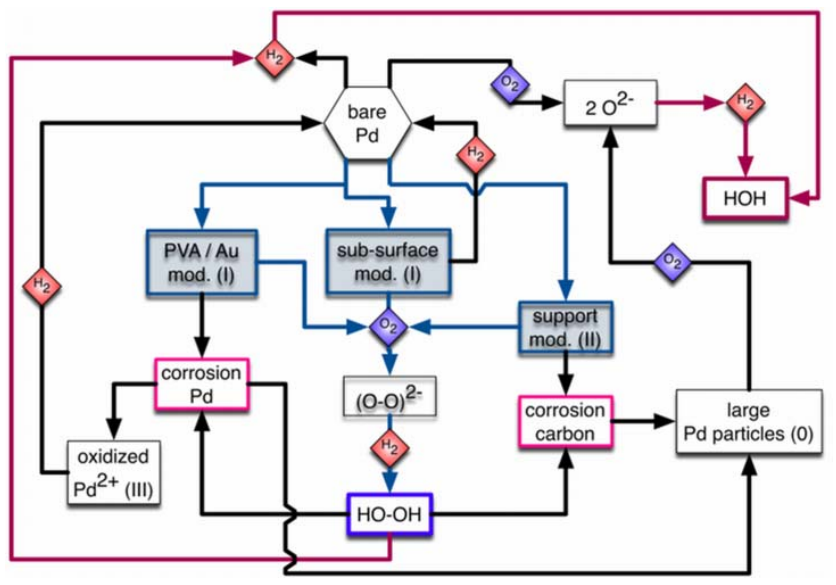

Scheme 2. Reaction system of $\mathrm{H}_{2} \mathrm{O}_{2}$ synthesis. The numbers in brackets refer to the XPS assignments discussed. The blue arrows designate the desired selective reaction path, the red arrows indicate the unselective deep hydrogenation and the black arrows refer to the structural deactivation pathways of the catalyst.

This work indicates the complex situation of a seemingly simple reaction of selective hydrogenation of di-oxygen. Scheme 2 summarizes the findings of the paper. Bare nano-Pd is converted either during synthesis or during initial operation into electronically modified $\mathrm{Pd}$ as sensed by $\mathrm{CO}$ chemsiorption and by XPS shifts. These modified Pd surfaces selectively activate di-oxygen to the peroxo species and simultaneously provide dissociated hydrogen. The result is the desired product $\mathrm{H}_{2} \mathrm{O}_{2}$. Bare Pd deeply activates di-oxygen to the oxo-anion and leads to the undesired product water.

Unfortunately $\mathrm{H}_{2} \mathrm{O}_{2}$ undergoes two pathways of deactivation processes. The simpler case is deep hydrogenation by contact of the product with excess hydrogen over non-modified Pd leading to water.

This pathway can be avoided by minimizing the abundance of bare Pd of any size. The other subtler pathway concerns the reaction of the product with the catalyst.

This path exhibits two lines of reaction. The oxidant $\mathrm{H}_{2} \mathrm{O}_{2}$ either reacts with the PVA protector and with bare $\mathrm{Pd}$ to form oxidic $\mathrm{Pd}^{2+}$ species. These species can become reduced by excess hydrogen spilling over from $\mathrm{Pd}$ metallic species and hence lead to re-structured $\mathrm{Pd}$ nanoparticles. A parallel reaction of the de-protected $\mathrm{Pd}$ particles is to form large $\mathrm{Pd}$ particles by coalescence as seen in TEM images. The resulting bare $\mathrm{Pd}$ of large size is undesired but less active than small bare $\mathrm{Pd}$ particles. It represents one likely terminal deactivation product of the catalyst.

Alternatively the $\mathrm{H}_{2} \mathrm{O}_{2}$ reacts with the carbon support preferably with those sites binding the $\mathrm{Pd}$ to the support. Here we found that certain nitrogen-containing active sites are resistant to oxidation and are simultaneously strong modifiers of the Pd towards selective oxidation. The generation of such sites in large abundance would be one strategy towards a stable and active catalyst for $\mathrm{H}_{2} \mathrm{O}_{2}$ synthesis. All other specific high-energy sites that are active in binding $\mathrm{Pd}$ either as oxygen or nitrogen functional groups are not stable over longer terms and are thus despite their initial high abundance not helpful to generate the stable active catalyst.

The operation conditions provide another means of controlling stability and productivity of the system. The semibatch process is unsuitable to derive reaction rate constants required to generate a quantitative model with predictive character for optimizing the correct flow rates, solvents, pressures and temperature that all regulate the optimal chemical potential of the system. Substantial progress is thus coupled to a change in operation conditions to a steady state process with continuous removal of the product $\mathrm{H}_{2} \mathrm{O}_{2}$. A last variable is the loading of the catalyst support with $\mathrm{Pd}$. This factor must not exceed the number of oxidation-resistant active sites times the composition of each Pd nanoparticle. The present loading was substantially too high for the quality of the carbon support. Would it be possible to generate a carbon form with a stable abundance of oxidation-resistant binding sites for $\mathrm{Pd}$ in the order of magnitude of NCNT_873 or even higher, then loading of $\mathrm{Pd}$ from direct deposition precipitation with a much lower nominal loading than the $1.6 \%$ applied here should be sufficient and beneficial simultaneously.

\section{Conclusions}

The paper has shown how multiple complex feedback mechanisms are organized between the $\mathrm{Pd}$-based catalyst and its reactants in the direct synthesis of $\mathrm{H}_{2} \mathrm{O}_{2}$, on one side, and the desired product with both catalyst and support, on the other 


\section{ChemSusChem}

\section{Full Papers \\ wrvw.chemsuschem.org}

side. Unexpected was the co-existence of pre-synthesized modified $\mathrm{Pd}$ with autogenously modified $\mathrm{Pd}$ by sub-surface reaction. The resulting phenomenological complexity is hardly seen in the catalyst performance, except for significant differences in performance of nominally rather similar systems. Multiple in-situ analysis by chemisorption and spectroscopy coupled to high-resolution morphological examination revealed the systemic interactions.

The deconvolution of these interactions allows us to provide recommendations towards optimization strategies of this reaction, such as via optimization of the support. Alloying, as another common form of synthetic optimization, proved to be less effective. Least effective is the predetermined size control of the active metal by using a polymer protective capping agent.

\section{Experimental Section}

\section{Catalysts preparation:}

CNT functionalization: The functionalization of the CNT (Pyrograf. Inc) was carried out as reported in.[18] Accordingly, $10 \mathrm{~g}$ of CNT (grade PR24PS) were suspended in $500 \mathrm{ml} \mathrm{HNO}_{3}$ conc. (70\% Sigma-Aldrich), heated to $373 \mathrm{~K}$ and kept at this temperature for $2 \mathrm{~h}$ followed by filtering, rinsing and drying overnight at $393 \mathrm{~K}$. Afterwards $10 \mathrm{~g}$ of the oxidized CNT were treated in $\mathrm{NH}_{3}(200 \mathrm{ml} / \mathrm{min})$ for $4 \mathrm{~h}$ to obtain NCNT. Two different NCNT batches were obtained: NCNT473K and NCNT873K were obtained by $\mathrm{NH}_{3}$ treatment at $473 \mathrm{~K}$ and $873 \mathrm{~K}$, respectively. These two batches of NCNT were used to immobilize the Pd and PdAu nanoparticles.

Preparation of $5 \mathrm{~g}$ of Pd monometallic samples (2 wt\%):

$\mathrm{Na}_{2} \mathrm{PdCl}_{4}$ from Aldrich $\left(99.99 \%\right.$ purity), $\mathrm{NaBH}_{4}(>96 \%$ purity) from Fluka and polyvinyl alcohol (PVA) (Mw $=13,000$ $23,000,87-89 \%$ hydrolyzed) from Aldrich were used. First, aqueous solutions of PVA (1wt\%) and $\mathrm{NaBH}_{4}(0.1 \mathrm{M})$ were prepared. $0.94 \mathrm{mmol}$ solid $\mathrm{Na}_{2} \mathrm{PdCl}_{4} .2 \mathrm{H}_{2} \mathrm{O}$ and $10 \mathrm{ml}$ of PVA solution were added to $250 \mathrm{ml}$ of $\mathrm{H}_{2} \mathrm{O}$ and mechanically stirred with a stirring rate of $1000 \mathrm{rpm}$. After $3 \mathrm{~min}$ of stirring, $40 \mathrm{ml}$ of a freshly prepared $0.1 \mathrm{M}$ solution of $\mathrm{NaBH}_{4}$ was added. The colloidal solution was then acidified with $2 \mathrm{ml}$ of $\mathrm{H}_{2} \mathrm{SO}_{4} 1 \mathrm{M}$ and the functionalized NCNT $(4.9 \mathrm{~g})$ were quickly added to the solution for the immobilization. The so-obtained suspension was kept under vigorous mechanical stirring for $1 \mathrm{~h}$. The samples were then filtered, washed and dried overnight at $353 \mathrm{~K}$.

Preparation of $5 \mathrm{~g}$ of bimetallic samples (total metal loading $2 \mathrm{wt} \%$, Au:Pd ratio wt/wt 90:10):

$0.45 \mathrm{mmol}$ solid $\mathrm{NaAuCl}_{4} .2 \mathrm{H}_{2} \mathrm{O}$ (Sigma-Aldrich 99.99\%) and $10 \mathrm{ml}$ of $1 \% \mathrm{w} / \mathrm{w}$ PVA were added to $250 \mathrm{ml}$ of $\mathrm{H}_{2} \mathrm{O}$ and mechanically stirred with a stirring rate of $1000 \mathrm{rpm}$. After $3 \mathrm{~min}$ of stirring $13.5 \mathrm{ml}$ of $0.1 \mathrm{M} \mathrm{NaBH} 4$ solution is added. The obtained colloid is then acidified with $2 \mathrm{ml}$ of $\mathrm{H}_{2} \mathrm{SO}_{4} 1 \mathrm{M}$ and the functionalized NCNT $(4.9 \mathrm{~g})$ were quickly added to the solution for the immobilization. The suspension was kept under vigorous mechanical stirring for $1 \mathrm{~h}$. The samples were then filtered and washed. The Au/NCNT sample was dispersed in $250 \mathrm{ml}$ of $\mathrm{H}_{2} \mathrm{O}$ and $0.094 \mathrm{mmol}$ solid $\mathrm{Na}_{2} \mathrm{PdCl}_{4} \cdot 2 \mathrm{H}_{2} \mathrm{O}$ was added to the solution. $\mathrm{H}_{2}$ was bubbled $(3 \mathrm{ml} / \mathrm{min})$ into this solution at atmospheric pressure and room temperature for $2 \mathrm{~h}$ under magnetic stirring. The slurry was then filtered washed and dried overnight at $353 \mathrm{~K}$.

\section{Catalytic test:}

All catalysts were tested at room temperature in the catalytic oxidation of $\mathrm{H}_{2}$ to $\mathrm{H}_{2} \mathrm{O}_{2}$ in a stirred stainless steel reactor coated with Teflon (capacity $300 \mathrm{ml}$ ) containing $35 \mathrm{mg}$ of catalyst in a fine powder form and $125 \mathrm{ml}$ of anhydrous $\mathrm{CH}_{3} \mathrm{OH}$ as a reaction medium. $125 \mu \mathrm{L}$ of $\mathrm{H}_{2} \mathrm{SO}_{4}$ were added for $\mathrm{H}_{2} \mathrm{O}_{2}$ stabilization. The autoclave operates in semi-batch conditions, e.g. continuous feed of the gas to the well mixed autoclave. The concentration of $\mathrm{H}_{2}$ was 9 vol\%, and the $\mathrm{O}_{2} / \mathrm{H}_{2}$ ratio was 7 . The ballast gas was $\mathrm{CO}_{2}$. The feed is continuously bubbled through the reaction medium at room temperature and at a total pressure of $3 \mathrm{MPa}$. Stirring (1300 rpm) was started after reaching the pressure of $3 \mathrm{MPa}$, and experiments were carried out for 180 min, monitoring both $\mathrm{H}_{2} \mathrm{O}_{2}$ and $\mathrm{H}_{2} \mathrm{O}$ concentration in the liquid phase, and $\mathrm{H}_{2}$ and $\mathrm{O}_{2}$ concentrations in the gas phase. The $\mathrm{H}_{2} \mathrm{O}_{2}$ decomposition tests were carried out in semi-batch at a total pressure of 3 MPa. The amount of $\mathrm{H}_{2} \mathrm{O}_{2}$ was 4800 ppm. $125 \mu \mathrm{L}$ of $\mathrm{H}_{2} \mathrm{SO}_{4}$ were added. The concentration of $\mathrm{H}_{2}$ was 9 vol\% in $\mathrm{N}_{2}$. Additional decomposition tests were carried on in $\mathrm{N}_{2}$. Gas analysis was performed using a gas chromatograph unit (Agilent $3000 \AA$ equipped with a Molsieve $5 \AA$ column using Argon as carrier gas). The reaction products were analyzed by potentiometric titrations of $\mathrm{H}_{2} \mathrm{O}_{2}$ (Metrohm, 794 Basic Trino) and $\mathrm{H}_{2} \mathrm{O}$ (Metrohm, $831 \mathrm{KF}$ Coulometer), respectively.

\section{Catalyst Characterization:}

The microstructure of the supports and catalysts was investigated by Transmission Electron Microscopy (TEM). High-resolution transmission electron microscopy (HRTEM) and high angle annular dark field scanning transmission electron microscopy (HAADF-STEM) have been performed with a TitanCs300 microscope from FEl equipped with Cscorrector from CEOS. The samples were dry-deposited on a holey carbon film supported on a Cu grid.

CO-chemisorption was carried out with a SETARAM MS70 Calvet calorimeter combined with a custom-designed high vacuum and gas dosing apparatus, which has been described in detail. ${ }^{\text {[73] }}$ The dosing volume is $139 \mathrm{ml}$, and an absolute pressure transducer (MKS Baratron type 121) measures pressure variations of $0.003 \mathrm{mbar}$ in this volume (provided the box temperature does not vary by more than $\pm 1.5 \mathrm{~K}$ ), allowing (as a conservative estimate) to dose as low as $0.02 \mu \mathrm{mol}$ into the sample cell. An all-metal cell was employed as described in. [74] The degassing of the samples was conducted inside the calorimeter cell. After evacuation at $313 \mathrm{~K}$ for $17 \mathrm{~h}$ to a pressure $\leq 10-8 \mathrm{mbar}$, the cell was closed. CO 3.7 (Westfalen) was introduced into the initially evacuated cell, and the pressure evolution and the heat signal were recorded for each dosing step. The adsorption isotherm was derived from the dosed amount and the equilibrium pressure (in comparison to an empty cell). The differential heats of adsorption were calculated by converting the signal area into a heat by using the calorimeter's calibration factor and then dividing the heat by the number of molecules adsorbed in this step. All data sets (consisting of one isotherm and the corresponding heats of adsorption) were obtained by treating a used sample, i.e. after $\mathrm{H}_{2} \mathrm{O}_{2}$ synthesis at $313 \mathrm{~K}$. The mean surface area of a $\mathrm{Pd}$ atom 
is taken as $0.0787 \mathrm{~nm}^{2} /$ atom (DIN66). The monometallic and bimetallic samples after 12 minutes of reaction were measured. Prior chemisorption the samples were outgassed for $17 \mathrm{~h}$ in $\mathrm{He}$ flow at $353 \mathrm{~K}$. Calibration of the heat/voltage constant of the microcalorimeter was accomplished by the Joule effect. The calibration of the volumes was carried out with $\mathrm{O}_{2}$ under the same conditions as for the adsorption procedure. We have adopted the calorimetric sign criterion (positive energetic quantity for an exothermic process). The samples were lightly pressed into pellets and cut into small pieces. The sieve fraction with diameters between 0.40 and $0.60 \mathrm{~mm}$ was used for all experiments inside the calorimetric cell.

The microcalorimetry reference experiments were carried as following: 1) $\mathrm{H}_{2}$ treatment: 1 bar, $24 \mathrm{~h}, 313 \mathrm{~K}$; 2) stepwise $\mathrm{CO}$ adsorption at $313 \mathrm{~K}$; 3) $\mathrm{H}_{2}$ reduction same conditions again: 1 bar, $24 \mathrm{~h}, 313 \mathrm{~K}$; 4) $\mathrm{O}_{2}$ treatment : 1 bar, $24 \mathrm{~h}, 313 \mathrm{~K} ; 5$ ) stepwise adsorption of $\mathrm{CO}$ at $313 \mathrm{~K} ; 6) \mathrm{H}_{2}$ reduction again: 1 bar, $24 \mathrm{~h}, 313 \mathrm{~K}$; 7) stepwise adsorption of $\mathrm{CO}$ at $313 \mathrm{~K}$.

XPS measurements were carried out at the in-situ end station ${ }^{[75]}$ of the ISISS beamline of BESSY II. The set-up consists of an in-situ chamber where the sample is placed for measurement under different reactive atmosphere and temperature. The temperature is measured by a K-type $\mathrm{Ni} / \mathrm{NiCr}$ thermocouple spot-welded onto the sample and temperature-programmed heating was done by an IR laser from the rear. The photo-emitted electrons enter, through an aperture, the differentially pumped electrostatic lenses section allowing performing in situ photoelectron spectroscopy up to 1 mbar total reactant pressures in the XPS chamber. Finally, photo-emitted electrons are detected with a SPECS hemispherical analyzer. The XPS measurements were performed applying a suitable excitation energy corresponding to $\mathrm{KE}$ of the photo-emitted electrons of $600 \mathrm{eV}$ and $150 \mathrm{eV}$ for the core levels Pd3d, Au4f, C1s, O1s and N1s. The energy pass Ep was normally set to $20 \mathrm{eV}$. The Pd3d envelopes were fitted using Casa XPS software after subtraction of a Shirley background. ${ }^{[76]}$ The fitting of the spectra was done constraining the peak position by $\pm 0.05 \mathrm{eV}$. The fitting of the Pd3d consists of 4 components $\mathrm{Pd}(0)$ and $\mathrm{Pd}(\mathrm{I})$ with Doniach-Sunjic (DS) line shape and $\mathrm{Pd}(\mathrm{II})$ and $\mathrm{Pd}(\mathrm{III})$ with Gaussian-Lorentzian (GL) line-shape. An area intensity ratio between the $P d 3 d^{5 / 2}$ and $\mathrm{Pd} 3 \mathrm{~d} 3 / 2$ spin orbit split transition was constrained to the theoretical value of 3:2 and the distance between the two spin orbit splitted transition was $5.3 \mathrm{eV}$. This approach was also used in the case of the bimetallic samples, which are more complicated due to the overlap between the $\mathrm{Pd} 3 \mathrm{~d}^{5 / 2}$ and the Au3d state. Binding energies (BEs) were generally referenced to the Fermi edge recorded after each core level measurement or the C1s BE. Quantification of the elemental composition was carried out according to homogeneous model distribution. For quantification the spectra have been normalized to the impinging photon flux. The measurements were mainly performed at room temperature and in UHV condition. When gas $\left(\mathrm{O}_{2}\right.$ and $\left.\mathrm{H}_{2} \mathrm{O}\right)$ was used the pressure was 0.1 mbar.

\section{Acknowledgements}

The authors aknowledge Dr. Emrah Yücelen from FEI Company and Dr. Marc Willinger at FHI for providing EDX_STEM mapping in Figure 3 AC at FEl, Eindhoven.
Keywords: Gold $\bullet \mathrm{H}_{2} \mathrm{O}_{2}$ direct synthesis $\cdot \mathrm{NCNT} \cdot$ Palladium nanoparticles $\cdot$ XPS

[1] F. Cavani, G. Centi, S. Perathoner, F. Trifirò, Sustainable Industrial Chemistry- Principles, Tools and Industrial Examples, Wiley $\mathrm{VCH}$ (Weinheim, Germany), 2009.

[2] G. Blanco-Brieva, M.C. Capel-Sanchez, M. Pilar de Frutos, A. PadillaPolo, J.M. Campos-Martin, J.L.G. Fierro, Jose L. G., Ind. Eng. Chem. Res. 2008, 47, 8011.

[3] G. Centi, S. Perathoner, S. Abate, Direct synthesis of Hydrogen Peroxide: Recent Advances, Edited by N. Mizuno, WILHEY VCH 2009.

[4] A. Pashkova, R. Dittmeyer, N. Kaltenborn, H. Richter, Chem. Eng. J. 2010, 165, 924-933.

[5] J. M. Campos-Martin, G. Blanco-Brieva, J. L. G. Fierro, Angew. Chem. Int. Ed. 2006, 45, 6962-6984.

[6] Q. Liu, K.K. Gath, J.C. Bauer, E.E. Schaak, J.H. Lunsford, Catal. Lett. 2009, 132, 342.

[7] S. Melada, F. Pinna, G. Strukul, S. Perathoner, G. Centi, J. Catal. 2006, 237, 213.

[8] J. Pritchard, M. Piccinini, R. Tiruvalam, Q. He, N. Dimitratos, J. A. Lopez-Sanchez, D. J. Morgan, A. F. Carley, J. K. Edwards, C. J. Kiely, G. J. Hutchings, Catal. Sci. Technol. 2013, 3, 308-317.

[9] J. K. Edwards, J. Pritchard, M. Piccinini, G. Shaw, Q. He, A. F. Carley, C. J. Kiely, G. J. Hutchings, J. Catal. 2012, 292, 227-238.

[10] J. K. Edwards, B. Solsona, E. Ntainjua, A. F. Carley, A. A. Herzing, C. J. Kiely, G. J. Hutchings, Science 2009, 323, 1037-1041.

[11] S. Abate, R. Arrigo, M. E. Schuster, S. Perathoner, G. Centi, A. Villa, Catal. Today 2010, 157, 280-285.

[12] S. Ladas, R. Imbihl, G. Ertl, Surf. Sci. 1989, 219, 88-106.

[13] R. J. Behm, V. Penka, M. - G. Cattania, K. Christmann, G. Ertl., J. Chem. Phys. 1983, 78, 7486.

[14] R. Imbihl, G. Ertl, Chem. Rev. 1995, 95, 697.

[15] D. Teschner J. Borsodi A. Wootsch Z. Révay M. Hävecker A. KnopGericke S. D. Jackson, R. Schlögl, Science 2008, 320, 86-89.

[16] D. Teschner, E. Vass, M. Hävecker, S. Zafeiratos, P. Schnörch, H. Sauer, A. Knop-Gericke, R. Schlögl, M. Chamam, A. Wootsch, A. S. Canning, J. J. Gamman, S. D. Jackson, J. McGregor, and L. F. Gladden, J. Catal. 2006, 242, 26.

[17] M. Ambruster et al.,ChemCatChem 2012,4, 1048-1063.

[18] P. Biasi, P. Canu, F. Menegazzo, F. Pinna, T. O. Salmilnd. Eng. Chem. Res., 2012, 51, 8883-8890.

[19] S. Abate, S. Perathoner, G. Centi, Topics in Catalysis 2012, 54, 718728.

[20] R. Arrigo, S. Wrabetz, M. E. Schuster, D. Wang, A. Villa, D. Rosenthal, F. Girsgdies, G. Weinberg, L. Prati, R. Schlögl, D. S. Su, Phys. Chem. Chem. Phys., 2012, 14, 10523-10532.

[21] A. Villa, Di Wang, P. Spontoni, R. Arrigo, D. Su, L. Prati, Catal. Today 2010, 157, 89-93.

[22] R. Arrigo, M. Hävecker, S. Wrabet, R. Blume, M. Lerch, J. McGregor, E. P. J. Parrott, J. A. Zeitler, L. F. Gladden, A. Knop-Gericke, R. Schlögl D. S. Su, J. Am. Chem. Soc. 2010, 132, 9616-9630.

[23] A.M. Venezia, L.F. Liotta, G. Pantaleo, V. La Parola, G. Deganello, A Beck, Zs. Koppány, K. Frey, D. Horváth, L. Guczi, Appl. Catal. A 2003, 251, 359-368.

[24] A. Villa, C. Campione, L. Prati, Catal. Lett. 2007,115, 133-136.

[25] M. Chen, D. Kumar, C. W. Yi, D. W. Goodman, Science 2005, 310, 291.

[26] D. Wang, A. Villa, F. Porta, D. Su, L. Prati, Chemm. Commun. 2006 1956.

[27] L. Prati, A. Villa, F. Porta, D. Wang, D. Su, Catalysis Today 2007, 122, 386-390.

[28] A. Villa, D. Wang, D. Su, G. M. Veithc, L. Prati., Phys. Chem. Chem. Phys., 2010, 12, 2183-2189.

[29] S. Abate, M. Freni, R. Arrigo, M. E. Schuster, S. Perathoner, G. Centi, Chemcatchem 2013, DOI: 10.1002/cctc.201200914

[30] J. Pritchard, L. Kesavan, M. Piccinini, Q. He, R. Tiruvalam, N. Dimitratos, J. A. Lopez-Sanchez, A. F. Carley, J. K. Edwards, C. J. Kiely, G. J. Hutchings, Languimir 2010, 26, 16568-16577. 


\section{ChemSusChem}

\section{Full Papers \\ www:chemsuschem.org}

[31] J. K. Edwards, G. J. Hutchings, Angew. Chem. Int. Ed. 2008, 47, 9192-9198.

[32] J. K. Edwards, A. F. Carley, G. J. Hutchings, Green Chem. 2012, 14, 170-181.

[33] manuscript in preparation for Angewandte Chemie

[34] D. Wang, A. Villa, P. Spontoni, D. S. Su, L. Prati, Chem. Eur. J. 2010 , 16, 10007-10013.

[35] K. Kloeger, W. Kleist, S. S. Proeckl, Inorg. Chem. 2007, 46 (18761883)

[36] R. Arrigo, M. Hävecker, R. Schlögl, D. Su, ChemmComm 2008, 40 4891-4893.

[37] B. E. Koel, A. Sellidj, Phys. Rev. B 46, 1992, 7846-7856.

[38] G. K. Weithereim, S. B. DiCenzo, D. N. E. Buchanan, Phys. Review B 1986, 33, 5384-5390

[39] M. G. Mason, L.J. Gerenser, S.-T.Lee, Phys. Rev. Lett. 1977, 39, 288-291.

[40] D. Zemlyanov, B. Aszalos-Kiss, E. Kleimenov, D. Teschner, S. Zafeiratos, M. Hävecker, A. Knop-Gericke, R. Schlögl, H. Gabasch, W. Unterberger, K. Hayek, B. Klötzer, Surf. Sci. 2006, 600, 983-994.

[41] H. Gabasch, K. Hayek, B. Klötzer, W. Unterberger, E. Kleimenov, D. Teschner, S. Zafeiratos, M. Hävecker, A. Knop-Gericke, R. Schlögl, B. Aszalos-Kiss, D. Zemlyanov, J. Phys. Chem. C 2007, 111, 7957-7962.

[42] R. C. Baetzold, J. F. Hamilton, Prog. Solid St. Chem. 1983, 15, 1-53.

[43] I. Aruna, B. R. Mehta, L. K. Malhotra, S. M. Shivaprasad, J. Appl. Phys. 2008, 104064308.

[44] L. Chen, A. Yelon, E. Sacher, J. Phys. Chem. C 2011, 115, 78967905.

[45] D. Teschner, A. Pestryakov, E. Kleimenov, M. Hävecker, H. Bluhm, H. Sauer, A. Knop-Gericke, R. Schlögl, J.Catal. 2005, 230, 186-194.

[46] Z. Li, Surf. Sci. 2007, 601, 1898-1908.

[47] E. H. Voogt, A. J. M. Mens, O. L. J. Gijzeman, J. W. Geus, Surface Science 1996, 350, 21-31.

[48] A. Thøgersen, J. Mayandi, L. Vines, M. F. Sunding, A. Olsen, S. Diplas, M. Mitome, Y. Bando, J. Appl. Phys. 2011, 109, 084329.

[49] Y. Takasu, R. Unwin, B. Tesche, A. Bradshaw, M. Grunze, Surf. Sci. 1978, 77, 219

[50] A. J. Pertsin, Y. M. Pashunin, Appl. Surf. Sci. 1990, 44, 171-178.

[51] M. Peuckert, J. Phys. Chem. 1985, 89, 2481-2486.

[52] Oliver Balmes et al, Phys. Chem. Chem. Phys., 2012, 14, 4796-4801.

[53] K. Otto, L. P. Haack, J. E. de Vries, Appl. Catal. B Environ. 1992, 11 12.

[54] L. Liu, F. Zhou, L. Wang, X. Qi, F. Shi, Y. Deng, J. Catal. 2010, 274, $1-10$.
[55] Z. Wang, T. Kong, K. Zhang, H. Hu, X. Wang, J. Hou, J. Chen, Mater. Lett. 2007, 61, 251-255.

[56] M. Hasik A. Bernasik, A. Drelinkiewicz, K. Kowalski, E. Wend, J. Camr, Surf. Sci. 2002, 507-510, 916-921; (b) M. Hasik, A. Bernasik, A. Adamczyk, G. Malata, K. Kowalski, J. Camr, Eur. Polym. J. 2003, 39, 1669-1678.

[57] J. Zhou, Y. Yang, L. Zhao, X. Li, R. Zhou, X. Zheng, Front. Chem. China 2009, 4, 142-148.

[58] H. F. Wang , W. E. Kaden , R. Dowler, M. Sterrer, H.-J. Freund, Phys. Chem. Chem. Phys. 2012, 14, 11525-11533.

[59] M. J Toebes, J. A. van Dillen, K. P. de Jong, J. Mol. Catal. A: Chem. 2001, 173, 75-98

[60] N. Krishnankutty, M.A. Vannice, J. Catal. 1995, 155, 312.

[61] N.Cardona-Martinez, J.A. Dumesci, Adv. Catal. 1992, 38, 14

[62] M. Baerns, Appl. Catal. A: Gen. 1997, 158, 163-183.

[63] J. M. Flores-Camacho, J. H. Fischer-Wolfarth, M. Peter, C. T. Campbell, S. Schauermann, H.-J. Freund, Phys. Chem. Chem. Phys., 2011, 13, 16800-16810

[64] I. V. Yudanov , A. Genest , S. Schauermann H.-J. Freund, N. Rösch Nano Lett., 2012, 12, 2134-2139.

[65] P. Chou, M. A. Vannice, J. Catal. 1987, 104, 17-30.

[66] V. Matolín, I. Jungwirthová, E. Tomková, Prog. Surf. Sci. 1991, 35, 175-178.

[67] I. Langmuir, JACS 1916, 38, 2221-2295.

[68] Q. Liu, K. K. Gath, J. C. Bauer, R. E. Schaak, J. H. Lunsford, Cat. Letter 2009, 132, 342-348.

[69] M. Roussel, H. Miinoun, J. Catal. 1980, 45, 5387.

[70] N.A. Khan, S. Shaikhutdinov, H.-J. Freund, Catal. Lett. 2006, 108, 159-164.

[71] W. C. Conner, J. L. Falconer, Chem. Rev. 1995, 95, 759-788.

[72] C.-Y. Chen, Int. J Hydrogen Ener. 2012, 37, 3305-3312.

[73] L.C. Josefowicz, H.G. Karge, E.N. Coker, J. Phys. Chem. 1994, 98, 8053-8060.

[74] E.N. Coker, H.G. Karge, Rev. Sci. Instrum. 1997, 68, 4521-4524.

[75] A. Knop, E. Kleimenov, M. Hävecker, Adv. Catal. 2009, 52, 213-272.

[76] N. Fairley, A. Carrick, in The Casa Cookbook - Part 1: Recipes for XPS Data Processing, Acolyte Science, Kinderton Close, High Legh, Knutsford, Cheshire, WA16 6LZ U.K., 2005.

Received: ((will be filled in by the editorial staff))

Published online: ((will be filled in by the editorial staff)) 


\section{ChemSusChem}

Entry for the Table of Contents (Please choose one layout)

Layout 1:

\section{FULL PAPER}

Pd clusters with a modified electronic structure as compared to bare $\mathrm{Pd}$ metal or $\mathrm{Pd}$ oxides allow selective active species for the direct synthesis of $\mathrm{H}_{2} \mathrm{O}_{2} . \mathrm{N}$ atoms in substitutional positions in the NCNT support accomplish the best strategy for the stabilization of the active $\mathrm{Pd}$.

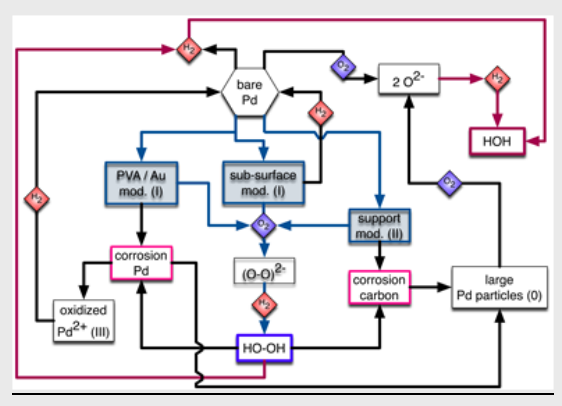

Rosa Arrigo, * Manfred E. Schuster, Salvatore Abate, Sabine Wrabetz, Kazuhiko Amakawa, Detre Teschner

Maria Freni, Gabriele Centi, Siglinda Perathoner, Michael Hävecker, Robert Schlögl, Page No. - Page No. Dynamics of $\mathrm{Pd}$ on nanocarbon in the direct synthesis of $\mathrm{H}_{2} \mathrm{O}_{2}$ 